\title{
Shallow-water hydrothermalism at Milos (Greece): Nature, distribution, heat fluxes and impact on ecosystems
}

Valentine Puzenat ${ }^{\mathrm{a}^{*}}$, Javier Escartin ${ }^{\mathrm{b}}$, Jean-Emmanuel Martelat ${ }^{\mathrm{c}}$, Thibaut Barreyre ${ }^{\mathrm{d}}$, Sven Le Moine Bauer ${ }^{\mathrm{d}}$, Paraskevi Nomikou ${ }^{\mathrm{e}}$, Nuno Gracias ${ }^{\mathrm{f}}$, Pascal Allemand $^{\mathrm{c}}$, Varvara Antoniou ${ }^{\mathrm{e}}$, Omer Coskun $^{\mathrm{g}}$, Rafael Garcia ${ }^{\mathrm{f}}$, Philippe Grandjean ${ }^{\mathrm{c}}$, Steffen Leth Jørgensen ${ }^{\mathrm{d}}$, Lluís Magif ${ }^{\mathrm{f}}$, Manolis Mandalakis $^{\mathrm{h}}$, William Orsi ${ }^{\mathrm{g}}$, Paraskevi Polymenakou ${ }^{\mathrm{h}}$, Anders Schouw ${ }^{\mathrm{d}}$, Guillem Vallicrosa ${ }^{\mathrm{f}}$ and Othonas Vlasopoulos ${ }^{\mathrm{e}}$.

${ }^{a}$ Université de Paris, Institut de physique du globe de Paris, CNRS, F-75005 Paris, France

${ }^{\mathrm{b}}$ Laboratoire de Géologie - CNRS, UMR 8538, École Normale Supérieure, PSL University, Paris, France

${ }^{\mathrm{c}}$ Université de Lyon, UCBL, ENSL, CNRS, Laboratoire de Géologie LGL-TPE, 69622, Villeurbanne, France

${ }^{\mathrm{d}}$ Department of Earth Science / Centre for Deep Sea Research, University of Bergen, Bergen, Norway

${ }^{\mathrm{e}}$ Faculty of Geology and Geoenvironment, National and Kapodistrian University of Athens, Athens, Greece

${ }^{\mathrm{f}}$ Underwater Robotics Research Center, Computer Vision and Robotics Institute, Universitat de Girona, Girona, Spain

${ }^{\mathrm{g}}$ Department of Earth and Environmental Sciences Palaeontology \& Geobiology, LudwigMaximilians-University of Munich, München, Germany 
${ }^{\mathrm{h}}$ Institute of Marine Biology Biotechnology and Aquaculture, Hellenic Center for Marine

Research, Anavyssos, Greece

* Corresponding author:

Valentine Puzenat

valentine.puzenat@gmail.com

Postal address: Institut de Physique du Globe de Paris - 1, rue Jussieu - 75238 Paris cedex 05 


\section{Abstract}

Submarine hydrothermal activity is responsible for heat and chemical exchanges through the seafloor. Shallow-water hydrothermal systems (SWHS), while identified around the globe, are often studied in a way that is less comprehensive than their deep-ocean counterparts (e.g., along ridges), where systematic optical and acoustic mapping is more prevalent and coupled to in situ observations and sampling. Using aerial drones, an AUV, and temperature measurements at 10$40 \mathrm{~cm}$ subseafloor, we investigated in 2019 one of the most extensive SWHS known to date, in Paleochori (south of Milos, Greece). Hydrothermal venting, found from the shore to water depths of almost $500 \mathrm{~m}$, shows emissions of gases and high-temperature fluids, often associated with bacterial mats and/or hydrothermal mineral precipitates. This study provides extensive drone mapping coupled with local AUV surveys for seafloor characterization and ground-truthing from the shore to $\sim 20 \mathrm{~m}$ water depth. Seafloor photomosaics also provide a detailed context to samples, measurements and observations carried in situ. We interpret the photomosaics to define distinct seafloor types, linked to this hydrothermal activity. White hydrothermal patches (WHPS) often show a clear polygonal organization, together with outflow areas that are both more dispersed and distributed. Polygonal patterns likely result from fluid convection in a sandy porous medium heated from below. These WHPS display elevated subseafloor temperatures, typically $>50{ }^{\circ} \mathrm{C}$, with maximum values of $\sim 75{ }^{\circ} \mathrm{C}$. Photomosaics also display textures of biological origin, including seagrass and bioturbation patterns. Widespread bioturbation by burrowing shrimps is often associated with WHPS, bounding them, but also occurs on sandy seafloor away from hydrothermal patterns. Subseafloor temperatures at these bioturbated areas are of $\sim 30-40{ }^{\circ} \mathrm{C}$, and are thus transitional between hot WHPS and sedimented seafloor unaffected by hydrothermal activity $\left(\sim 24^{\circ} \mathrm{C}\right)$. In addition to linking subseafloor temperature data and interpreted seafloor 
photomosaics, our results provide a comprehensive general overview of this SWHS, of the organization of its hydrothermal outflow through the seafloor, and of the underlying subseafloor fluid circulation. This paper also gives the first perspectives on the heat fluxes of the system, and constitutes a background for other studies on the nature and distribution of microbial communities, controlled by this hydrothermal activity.

Keywords: Milos, shallow-water, hydrothermalism, AUV, drone, photomosaics 


\section{Introduction}

The circulation of fluids in the Earth's lithosphere is often driven by heat sources at depth, and much of this activity occurs underwater. Hydrothermal circulation drives heat and chemical exchanges through the seafloor, is associated with water-rock reactions at depth and sustains numerous ecosystems. To constrain the setting and overall structure of these hydrothermal systems, detailed optical surveys of the seafloor are needed for a comprehensive geological mapping. These data are also crucial to understand the distribution, geometry and nature of hydrothermal outflow through the seafloor, and to extrapolate local observations (e.g., temperature and chemical measurements) in order to evaluate the associated mass, thermal and chemical fluxes (e.g., Price et al., 2013; Callac et al. 2017). Systematic and comprehensive mapping also provides a baseline for temporal studies, providing a context for in situ measurements, and establishing the links between hydrothermal activity, ecological and biological processes. To date, this is done partially in deep water settings (e.g., Maki et al., 2008; Barreyre et al., 2012; Marcon et al., 2013), but such mapping studies are less developed in shallow-water hydrothermal systems. While abundant and particularly ubiquitous at volcanically active areas (e.g., Tarasov et al., 2005; Price and Giovannelli, 2017; Martelat et al., 2020), their geometry, temporal evolution, and associated fluxes are yet not well constrained. Systematic and comprehensive mapping of shallow-water systems to date is therefore partial and limited to a few sites (e.g., Khimasia et al., 2020; 2021).

Here we present a comprehensive study on the organization of hydrothermal outflow at the shallow water hydrothermal system off the coast of Milos (Greece). Numerous sites around Milos extend to depths of $>200 \mathrm{~m}$, and several studies have investigated those on the south-eastern coast of the island over the last few decades (e.g., Aliani et al., 1998a; Aliani et al., 2004; 
Valsami-Jones et al., 2005; Price et al., 2013). These sites are most visible in sedimented, sandy seafloor, where hydrothermal outflow is associated with bacterial mats and hydrothermal precipitates. Therefore, prior studies have focused primarily on the associated geochemical and microbiological processes (e.g., Callac et al., 2017; Price and Giovannelli, 2017; Houghton et al., 2019; Megalovasilis, 2020). While earlier studies have provided maps with distribution of active venting areas extending from the shore to deep regions (e.g., Dando et al., 1995b), the actual geometry and distribution of sites and venting areas are poorly constrained. Only recently we have obtained detailed and accurate mapping of the Milos hydrothermal system to depths of $\sim 20$ m using satellite imagery (Martelat et al., 2020), and drone aerial imagery coupled with both temperature measurements and fluid chemistry (Khimasia et al., 2020; 2021). Here we use underwater surveys to adequately ground truth interpretation of drone imagery, and to provide a detailed context where temperature measurements can be precisely linked to the observed seafloor patterns. This approach, that differs from that of prior studies, allow us to correlate directly spatial patterns of seafloor hydrothermal activity and subseafloor temperature.

For this study we have thus conducted extensive aerial drone surveys at the Milos nearshore sites of Agia Kyriaki and Spathi Bay, in addition to Paleochori Bay, the main study site. The resulting aerial photomosaics provide a regional overview of the distribution of hydrothermal activity at these sites, complementing the prior study of Khimasia et al. (2020) at Paleochori bay, and extending it to adjacent areas. Drone surveys are coupled with Autonomous Underwater Vehicle (AUV) surveys to generate high-resolution seafloor photomosaics that are used for seafloor characterization and ground-truthing of the broader aerial drone seafloor imagery. Drone and AUV data reveal the detailed organization of hydrothermal activity at these sites and their link to associated ecosystems. We completed our study with subseafloor temperature measurements, 
sampling (sediment cores), and in situ observations carried out by divers at Paleochori Bay. These observations and measurements are thus carefully located relative to the structure and organization of hydrothermal outflow at specific sites imaged by drone or AUV.

With the analysis and interpretation of drone and AUV imagery, temperature measurements, and in situ observations, we discuss (a) seafloor hydrothermal patterns and their links with subseafloor hydrothermal circulation, (b) the correlation of temperature records with these patterns, that can subsequently be used in hydrothermal heat flux quantification, and (c) the study of seafloor patterns and temperature data to provide information on the spatial associations of certain ecosystems with hydrothermal activity. While the in situ observations, measurements, and samples were acquired at Paleochori Bay, they allow us to propose a general, regional overview of the shallow water hydrothermal system of Milos, and to discuss the organization of hydrothermal outflow, its nature and spatial distribution. Our results may also constrain the organization of hydrothermal outflow at other systems in sedimented areas, and provide a context to adequately constrain heat fluxes. 


\section{Geological background}

Milos (Greece) is located at the central part of the Hellenic Volcanic Arc, where the African plate subducts beneath the Aegean micro-plate (Figure 1). In this particular volcano-tectonic setting, numerous volcanic areas often show intense hydrothermal activity with underwater manifestations (e.g., Methana, Santorini, Milos, Kos; Dando et al., 2000). Among these, Milos hosts one of the most important and extensive shallow-water hydrothermal system known to date (Fytikas et al., 1986; Papanikolaou et al., 1993; Dando et al., 1995a; Aliani et al., 2004; Nomikou et al., 2013). At Paleochori Bay (SE of Milos island, Figure 1), known hydrothermal venting is distributed over a wide region from the shore to deeper areas, as identified both during ROV dives (Nomikou et al., 2013), and as gas flares at water depths of at least $300 \mathrm{~m}$ (Dando et al., 1995b; Dando et al., 2000). Additional venting sites have been identified around the island (Martelat et al., 2020) but with no detailed image surveys (e.g. using aerial drone in the shallow water, or underwater imagery).

Hydrothermal venting at Paleochori displays emissions of high temperature fluids of low $\mathrm{pH}$ and varying chlorinity, involving free gases $\left(\mathrm{CO}_{2}, \mathrm{H}_{2}, \mathrm{H}_{2} \mathrm{~S}, \mathrm{CH}_{4}\right)$ that are variably mixed with seawater (Dando et al., 1995b; Valsami-Jones et al., 2005). Fluids are saline and sulphidic, depleted in $\mathrm{Mg}^{2+}$ and $\mathrm{SO}_{4}{ }^{2-}$ and particularly enriched in $\mathrm{As}$ and $\mathrm{CO}_{2}$, in addition to $\mathrm{Na}^{+}, \mathrm{Ca}^{2+}, \mathrm{K}^{+}$, $\mathrm{Cl}^{-}, \mathrm{SiO}_{2}$ and other dissolved gases (Fitzsimons et al., 1997; Valsami-Jones et al., 2005; Price et al., 2013). Hydrothermal venting is often associated with orange and white precipitates of bacterial and hydrothermal mineral origin, which are respectively composed of As-sulfide and a mix of silica and sulfur (Price et al., 2013, Yücel et al., 2013; Godelitsas et al., 2015; Callac et al., 2017; Durán-Toro et al., 2019; Houghton et al., 2019; Khimasia et al., 2021). Since these white seafloor areas are highly reflective, hydrothermal seafloor textures can be mapped subaerially 
using satellites (Martelat et al., 2020), or drones (Khimasia et al., 2020). A recent satellite study has thus documented hydrothermal activity at and around Paleochori and on the North-East coast of Milos island (Martelat et al., 2020), but this study is limited to water depths of $<20-30 \mathrm{~m}$. Venting at other sites is documented from water column plumes identified in echo sounding profiles (Dando et al., 2000). Satellite imagery also reveals an apparent stability of the geometry and extent of these sites over time scales of a few years to a decade, both at Paleochori and at other areas around Milos (Martelat et al., 2020).

Heat, mass, and chemical fluxes are important to understand the dynamics of hydrothermal systems. Seafloor and subseafloor temperatures have been measured locally at Paleochori (e.g. Aliani et al., 1998b; Aliani et al., 2004; Valsami-Jones et al., 2005), and recent papers report systematic temperature measurements coupled to geochemical observations (e.g., Khimasia et al., 2020; 2021; Megalovasilis, 2020), with an associated mass flux for Paleochori estimated at $\sim 11300 \pm 1100 \mathrm{~m} 3 /$ day (Khimasia et al., 2021). These measurement sites cannot be spatially collocated with seafloor structures (imaged by either drone or AUV), as required by our approach to establish a reliable flux estimate that takes into account the geometry of outflow at the seafloor. Gas flow rates have been measured at individual gas vents (Dando et al., 1995b; Botz et al., 1996; Megalovasilis, 2020). As available measurements are discrete and punctual, and lacking constraints on the density and distribution of degassing, we cannot extrapolate these values regionally. 


\section{Methods}

The data used in this paper were acquired during two field work operations: Drone and Autonomous Underwater Vehicle (AUV) images were collected in June 2019, and completed in September 2019 with additional drone imagery, in situ temperature measurements, seafloor sampling as well as photos and videos from divers and GPS positions at the surface during all operations. We conducted studies over a wide range of scales, including satellite (Martelat et al., 2020), drone, AUV, and in situ images (Figure 2), together with in situ measurements and samples. Study areas along the SW shore of Milos included Agia Kyriaki, Spathi and Paleochori Bays. At this latter site we conducted a focus study on a polygonal hydrothermal pattern, as detailed below. The sampling of sediments and associated microbial ecosystems will be the scope of another study focusing on the links between microbiology and the thermal and chemical environment controlled by this hydrothermal activity.

\subsection{Seafloor mapping}

The distribution, nature and geometry of the seafloor hydrothermal structures and features reveal the organization of subseafloor hydrothermal circulation. A systematic mapping of our drone and AUV imagery at different scales, groundtruthed by in situ images and observations (Figure 2), is thus required to characterize precisely the different seafloor textures and their distribution, linking them to hydrothermal processes.

\subsubsection{Drone imagery}

Drone surveys at Agia Kyriaki, Paleochori and Spathi Bays (Figure 1) were conducted using two drones: a Phantom Pro (weight $1.4 \mathrm{~kg}$, Camera FC6310 $8.8 \mathrm{~mm} 20 \mathrm{Mpix}$ ) and a Mavic Pro (weight $0.907 \mathrm{~kg}$, Camera L1D-20c $10.26 \mathrm{~mm} 20 \mathrm{Mpix}$ ). Surveys were pre-programmed before 
take-off and flown on automatic mode. We processed and photomosaiced drone imagery using the Agisoft software to obtain orthophotos with a resolution of $\sim 10 \mathrm{~cm}$ per pixel. Away from the shore some images failed to be aligned as we lacked clear seafloor markers for matching. In these cases, images were visually inspected and manually aligned. Best images were usually acquired at sunrise around 05:30 am, with no or limited sun reflection on the sea surface, and with low winds. Images taken later during the day displayed more contrast visually but sun reflections were present in $\sim 30 \%$ of the individual images. As for satellite imagery (Martelat et al., 2020), drone image quality also depends on water turbidity. The areas covered in the drone surveys are shown in Figures 1 and S1 and a summary of information from each area is shown in Figure 3.

We visually identified and defined several seafloor types, based solely on the visual inspection of drone imagery. First, the most prominent pattern is seafloor with white patches of hydrothermal origin, named White Hydrothermal Patches (WHPs) from here on, as shown in Figures 2 and 3. Throughout the study area the intensity and homogeneity of these patches vary significantly, and hence their visual appearance also displays significant variability. We thus define three subcategories based on the reflectivity and whiteness of the seafloor (High, Medium, and Lowdensity WHPs, Figure 3). Second, we observe patches of darker material that seem to be closely associated to the WHPs, with similar patterns and geometrical arrangements, named Dark Hydrothermal Patches (DHPs) from here on (Figures 3e, 3f). Associated to DHPs we repeatedly identify clear linear features, often bounding WHPs instead of forming broad and diffuse patches, that are here identified as Dark Lines (Figures 3a, 3b). Lastly, we map dense meadows of seagrass that correspond to Posidonia oceanica (Figure 3), based both on prior studies (Aliani et al., 1998b, Martelat et al., 2020) and in situ field observations. Both the shapefiles that we have 
generated and the drone mosaics used in this study are provided in open access (see Data Availability Statement below for details).

\subsubsection{AUV imagery}

We used the SPARUS II Autonomous Underwater Vehicle (AUV, Carreras et al., 2018) from the University of Girona (Spain) to image the seafloor at a resolution higher than that of drone imagery, and to gather direct seafloor images for ground-truthing. We conducted a total of 25 AUV surveys at both Paleochori and Spathi Bays (See Figures 1 and S2). The AUV was programmed to follow lawn-mower patterns, flying at an altitude of $\sim 5 \mathrm{~m}$ above the seafloor. The combined total AUV track flown during the surveys was $\sim 41 \mathrm{~km}$.

Preliminary optical photomosaics were created in the field for data quality checks, using only the AUV navigation information. Final AUV photomosaics were created offline using image registration and pose-graph optimization (Elibol et al., 2010). This processing also uses the AUV navigation information (Campos et al., 2016), and thus provides a general georeferencing of the mosaic. As the surveyed seafloor was generally flat with limited local relief, a 2D image reconstruction approach was preferred over of a full 3D reconstruction. This optimized the handling of low-overlap images that hinder 3D reconstructions (Gracias et al., 2017). Final mosaics were blended (Prados et al., 2012) and rendered with a ground resolution ranging from 3 to $10 \mathrm{~mm}$ per pixel, compared to the $6-10 \mathrm{~cm}$ per pixel resolution of drone imagery.

As the AUV navigation is primarily inertial, there is an inherent vehicle drift, and as a result AUV photomosaics, while generally well-placed, display both spatial shifts and mild distortions relative to drone photomosaics. To work on a geographically consistent dataset, we shifted and 
wrapped the AUV photomosaics relative to the drone ones using tie points (Figure S3), generating a new set of AUV seafloor mosaics co-registered with drone imagery.

We divide AUV photomosaics into three zones: Paleochori West, Paleochori East and Spathi. Seafloor textures, digitized at a scale of 1:40, are identified solely based on the AUV imagery, and are briefly described here. First, as on drone mosaics, patches of white seafloor are highly reflective. We also refer to them as White Hydrothermal Patches (WHPs, Figure 4), defining three subcategories based on their density and reflectivity (Figure 4d). WHPs - High density are patches with highly reflective white material, with no sediments visible within. WHPs - Medium density are patches of less reflective white material, locally discontinuous, showing within sediments and associated textures (e.g. ripple marks). WHPS - Low density correspond to sediments showing clear ripples through discontinuous white materials. The boundaries of these textures, and particularly those of low density, are gradual on both AUV and scuba diver imagery. To define and digitize the limits of these textures, we evaluated them visually throughout the different AUV photomosaics and at different scales. We also observe patches of darker material in Spathi Bay (Figures 4e, 4f), here referred to as Dark Hydrothermal Patches (DHPs), as well as Dark Lines (Figures 4e, 4f) that are similar to the patterns defined above from the drone photomosaics.

The high resolution of the AUV relative to drone imagery allows us to identify substrates of biological origin that are not observable in drone photomosaics. First, we observe continuous zones of sediment mounds of up to a few tens of $\mathrm{cm}$ in diameter. These mounds often surround the White Hydrothermal Patches but are also found on sandy seafloor lacking hydrothermal patterns. Here we refer to this seafloor texture as Bioturbation (Figure 4). Second, we observe meadows of Posidonia oceanica (Figures 4e, 4f), also identifiable on drone photomosaics, and 
reported in prior studies of the area (Aliani et al., 1998b; Martelat et al., 2020). Lastly, we can identify another type of seagrass that forms sparse meadows with visible sandy seafloor corresponding to Cymodocea nodosa (Figure 4c, 4d, Aliani et al., 1998b). These Cymodocea meadows show significant variations in density and often disappear gradually. Here we digitize the densest patches only, determining boundaries based on their optical appearance at multiple scales. The digitized shapefiles and the uncorrected and corrected AUV photomosaics (coregistered with the drone photomosaics) are provided as open-access data (see Data Availability Statement below for details).

\subsubsection{Surface quantification from drone and AUV imagery}

The seafloor features described above were digitized as polygons or lines in QGIS. This digitization allows us to estimate the surfaces covered by the different seafloor types, and to investigate their spatial relationships. Resulting shapefiles were then used to create binary grids (resolution of $10 \mathrm{~cm}$ ) for each substrate type on both drone and AUV data ( 0 being the absence of substrate, and 1 the occurrence of this substrate). These binary grids facilitate calculations and analyses of seafloor surfaces (performed in MATLAB ${ }^{\circledR}$ ), which are reported in Tables 2 and 3. We also report in Table 4 surfaces from drone imagery calculated solely over AUV survey areas. As discussed below, quantitative comparisons of AUV and drone interpretation are critical to validate the extrapolation of local AUV observations to regional scales, using drone imagery.

\subsection{Temperature measurements and processing}

We used different autonomous temperature sensors to measure subseafloor temperature. Sensors have a rod with a thermocouple at their tips, and a housing with the data logger and batteries (Figures 5b, 5c, Figure 6a). In this experiment we deployed two WHOI-MISO high-temperature 
sensors, one WHOI-MISO low-temperature sensor, four NKE S2T6000DH-Ti high-temperature sensors and three NKE S2T6000D low-temperature sensors (see details in Table 1).

We also combined instruments to measure subseafloor temperature at different depths and obtain vertical temperature gradients (Tables S1 and S2). These included a set of 3 NKE instruments, named "Poseidon" from here on (Figure 6a), and two sets of 2 NKE sensors named "Set 1" and "Set 2". We also deployed a thermal blanket to measure the heat flux at the center of a polygonal hydrothermal cell (Figure 11). The thermal blanket includes two high-precision Antares thermistors $\left(-4-50{ }^{\circ} \mathrm{C}\right.$, accuracy of $\mathrm{r} 0.001{ }^{\circ} \mathrm{C}$, sampling rate of $2 \mathrm{~s}$, see Salmi et al., 2014), at the bottom and top of the blanket, separated by the blanket material. As the thermal conductivity of the blanket material is known, heat flux $F$ can be estimated using Fourier's Law $(F=-k d T(z) / z$, where $k$ is the thermal conductivity, $T$ the temperature, and $z$ the depth).

Sensors were deployed in September 2019, solely at Paleochori Bay (Figure 1), to obtain records ranging from a few seconds to days. Instruments were synchronized before and after their deployment, and the time was subsequently corrected assuming a linear time clock drift between the two synchronizations (see details in Barreyre et al., 2014). Deployments details are given in Tables S1 and S2, and examples of short-term deployments are illustrated in Figure 6b. The temperature data processing strategy described below depends on the record length, and is reported in Table S1 and Table S2.

The thermal blanket and the sensor WHOI-HiTT-018 were deployed over two days and their records are thus considered as "long-term deployments". The record from sensor WHOI-HiTT018 is stable, and Table S1 reports the average of the whole 27 hours record. The thermal blanket 
sensors showed mild temporal variations at the end of the record $\left(\sim 0.8^{\circ} \mathrm{C}\right.$ in amplitude), and this record section was excluded to calculate the average reported in Table S1.

We visually inspected the temperature records identified as "mid and short deployments" (several seconds to several hours) to determine if they reach a stable temperature (i.e., if thermal equilibrium with the subseafloor is achieved), or if temperature is still evolving at the end of the record (i.e., thermal equilibrium not reached). When temperature reaches equilibrium, we report the average of the last minute (Figure 5a, Figure 6b). For deployments still showing a mild temperature evolution but approaching thermal equilibrium and a stable temperature, we report the average over a shorter period of time at the end of the record, that is defined in each case based on temperature evolution. The averaging time windows vary between 5 to 30 seconds, and the resulting temperatures should be close to but slightly lower than the actual subseafloor temperatures (see details and values in Table S1 and Table S2). For deployments with significant temperature evolution at the end of the record, we report the last temperature value instead, which therefore corresponds to a minimum temperature estimate of the equilibrium temperature.

In addition to the subseafloor temperatures and the processing used to obtain them (see above), we include in Table S1 and Table S2 other observables that are key to correlate these temperatures to the patterns of hydrothermal outflow.

First, we provide positions of temperature measurements obtained from surface GPS positions. These have errors associated with offsets between surface and seafloor positions, in addition to inherent GPS errors. GPS readings were obtained with hand-held GPS units (Garmin GPSMAP62), operated by a diver at the surface over the instrument deployment site. Tables S1 and S2 also report temperature measurement positions relative to the drone and AUV 
photomosaics presented in this study. This position is determined using QGIS after locating each deployment on the drone and AUV photomosaics, and based on field observations and scuba diver imagery. Divers acquired both video and still imagery at deployments, allowing us to precisely identify and correlate structures observed in situ with those on the drone and AUV photomosaics. With the positions extracted from the photomosaics, we obtain a consistent geographic co-registration between temperature measurements, geological interpretations from the photomosaics, and in situ observations and measurements performed by divers.

Second, we also assigned to each deployment a seafloor type as classified from AUV and/or in situ observations (e.g., Figure 5b, 5c). Reported seafloor types correspond to those identified in AUV photomosaics, as described above, in addition to transitional ones for measurements at boundaries between seafloor patterns, and to other areas associated with venting that cannot be identified in the AUV or drone mapping. First, we acquired temperature records within the White Hydrothermal Patches (WHPs) and Bioturbation (BT) zones. The limit between WHPs and Bioturbation zones, when adjacent, is often gradual and not sharply defined. We thus establish a transitional category $(W H P s / B T)$. We also installed temperature sensors in sedimented seafloor unaffected by hydrothermal activity, that is classified as Non-hydrothermalized Sand (NS) from here on. We assign measurements to Hydrothermal Sand $(H S)$ when the seafloor shows significant coloration (ochre or grey primarily) from hydrothermal precipitation that is not imaged in the drone or AUV photomosaics. Lastly, we report an additional category, Fluids $(F L)$, for all measurements conducted directly at bubble outflows or in brine seeps, and therefore in areas of active and focused hydrothermal outflow.

Third, the subseafloor depth of the temperature measurements is determined from markers on temperature sensor rods, placed at known distances from their tips. Using field observations and 
underwater imagery acquired during deployments, we determine the depth of temperature measurements during deployments.

Fourth, Table S1 and Table S2 report the vertical temperature gradients acquired using the thermal blanket and the sets of instruments Poseidon, Set 1, Set 2, that in fine are required to calculate local heat fluxes. Thermal gradients are calculated using a least-square fit to the reported temperatures and their depths. Table S1 and Table S2 also include the goodness-of-fit to identify thermal profiles that are non-linear or show no clear thermal gradients with depth (Figure 6c). Table 5 reports the ranges and averages of temperatures and thermal gradients for each seafloor type. To calculate heat fluxes from these gradients, and to understand the relationship between conductive and advective processes, among other parameters we require constraints on the thermal conductivity of subseafloor sediment, which was not measured during this experiment.

Temperature at Paleochori Bay was measured at different subseafloor depths, depending on probe length and its insertion by the divers. As temperature gradients in the study area can be high (in many cases $>10{ }^{\circ} \mathrm{C} / \mathrm{m}$, and as high as $400{ }^{\circ} \mathrm{C} / \mathrm{m}$ ), we discuss and interpret subseafloor temperature patterns based on temperature data normalized to a subseafloor depth of $35 \mathrm{~cm}$. For sites occupied by the combined set of instruments ('Poseidon', 'Set 1' and 'Set 2'), we report the interpolated temperature at a depth of $35 \mathrm{~cm}$. For individual temperature probe deployments lacking temperature gradients we used instead the maximum thermal gradients measured from each seafloor type. We then provide a minimum and maximum temperature at $35 \mathrm{~cm}$ subseafloor, calculated using these gradients and the measured temperature (Table 5, Table S1, Table S2). 


\section{Results}

\subsection{Seafloor textures}

\subsubsection{Drone photomosaics}

The clearest seafloor structures visible on drone imagery are those associated with hydrothermal activity, in addition to biological patterns such as Posidonia oceanica meadows (Figure 3, Figure 7). Systematic mapping of different seafloor features on the drone photomosaics at the three study (Paleochori Bay, Agia Kyriaki, and Spathi Bay, see Figure 7) constrains surfaces and proportions of the different seafloor patterns (Table 2).

The WHPS cover $\sim 5 \%$ of the drone-surveyed seafloor at Paleochori Bay (Figure $7 \mathrm{a}$ ), $\sim 8 \%$ at Agia Kyriaki (Figure 7b), and $<2 \%$ at Spathi Bay (Figure 7c). The DHPs cover a much lower proportion of the surveyed seafloor, and account for $<1 \%$ at Spathi Bay. These estimates exclude the Dark Lines visible at the three bays, often crossing and/or bounding WHPs (see Figure 3). The DHPs reported in Table 2 underestimate surfaces and are thus a minimum value. Posidonia oceanica meadows show an uneven distribution both within each bay (Figs 3, 7,8), and vary in abundance among the different bays, ranging from a maximum of $\sim 12 \%$ at Spathi Bay, $\sim 3 \%$ at Paleochori, to a minimum at Agia Kyriaki with meadows covering $<1 \%$ of the surveyed seafloor.

Khimasia et al. (2020) identified at Paleochori Bay zones of 'Bacterial mats' and 'Former Bacterial mats'. While in some areas these 'Bacterial mats' correlate well with our WHPs, we identify structures (e.g., Dark Lines) that are not mapped in the Khimasia et al. (2020) study. This study also identifies 'Sea Grass', that correlate well with some of the main Posidonia meadows we identify, but in other areas Khimasia et al. (2020) reports features that are absent in our photomosaic. While some differences in the interpretation between studies may be attributed to 
criteria used in the classification, other differences may reflect instead temporal changes, that are out of the scope of this paper. For comparison, the 'Bacterial mats' identified by Khimasia et al. (2020) correspond to slightly less than $2 \%$ of the mapped seafloor, about half of the surface that we identify here as WHPs. Similarly, the seafloor this prior study identifies as 'Sea Grass' is $\sim 2 \%$, somewhat lower than the $3 \%$ of Posidonia oceanica that we interpret in our drone data.

\subsubsection{AUV photomosaics}

The high resolution of AUV photomosaics, acquired at a few meters above the seafloor, provide imagery of higher resolution than the one from the drone, without the water-column filter and sea surface illumination artifacts. These AUV data adequately image the seafloor textures described above, along with additional ones of biological origin not identified on drone photomosaics. While AUV-surveyed surfaces are much smaller than those from drone (see Figure 1), the overlapping imagery allows ground-truthing and facilitates the extrapolation of local AUV observations to broader areas covered by drone photomosaics. AUV surveys were conducted East and West of Paleochori Bay, and at Spathi Bay, with no surveys at Agia Kyriaki (Figure 8).

In Paleochori West (Figure 8b), WHPS of High-, Medium- and Low-density cover $\sim 34 \%$ of the surveyed area (Table 3$)$. Here we also mapped broad areas of bioturbated seafloor $(\sim 32 \%$, Table 3). This seafloor pattern lacks clear bacterial mats or hydrothermal precipitates but its geometry and distribution show that it is often associated with hydrothermal activity: Bioturbated areas bound and outline High- and Medium-density WHPs, and often develop in association with Lowdensity WHPs. Additionally, light patches of the seagrass Cymodocea nodosa, covering $\sim 11.5 \%$ of the Paleochori West photomosaic, often bound WHPs. 
In Paleochori East (Figure 8a), WHPs of High-, Medium- and Low-density cover a significant proportion of the surveyed seafloor ( $\sim 3 \%$, Table 3 ). Bioturbation covers $\sim 35 \%$ of the surveyed seafloor (Table 3). As at Paleochori West, these areas often develop over Low-density WHPs and bound the High- and Medium-density WHPs, particularly in the region showing clear polygonal patterns (northeast of the mosaic, Figure 8a). Bioturbation is also found away from any recognizable hydrothermal seafloor pattern. Finally Cymodocea nodosa patches are distributed throughout the area, often bounding WHPs, but covering much less surface than at Paleochori West $(<2.5 \%)$.

At Spathi Bay (Figure 8c), High- and Medium-density WHPs are limited ( $<4 \%$, Table 3). We clearly identify seafloor areas that correspond to Dark Hydrothermal Patches ( $1.7 \%$; Table 3), in addition to Dark Lines that frame the WHPS. Bioturbated areas $(\sim 7.2 \%)$, both bound WHPS, and develop away from any hydrothermal patterns, as observed in Paleochori. AUV surveys at Spathi Bay also mapped a broad meadow of the seagrass Posidonia, covering here $\sim 26 \%$ of the surveyed seafloor.

\subsubsection{Drone vs AUV mapping}

Quantitative comparison of imagery and interpretations from drone and AUV data is necessary to determine if the patterns identified in these different datasets are equivalent despite the differences in imaging conditions, or cannot be directly correlated. This is also required to extrapolate local AUV data to regional scales. Table 4 provides the comparison of surfaces for equivalent AUV and drone-derived seafloor patterns at Paleochori West, Paleochori East and Spathi. These reported surfaces correspond to those from the AUV surveys on the one hand, and to those interpreted on the aerial drone photomosaics but solely over the surfaces surveyed by the 
AUV, on the other hand. In Paleochori West and East we compared mapped surfaces for WHPS with all density combined. In Spathi bay we compared the surfaces of DHPs and Posidonia oceanica, in addition to the WHPs. As shown in Figure 9, the surfaces of interpreted seafloor patterns from both AUV and drone show extremely consistent values, with a slight overestimation of Posidonia oceanica surface on the drone imagery relative to the AUV, and a slight underestimation of the WHPs at Paleochori East, also on the drone imagery. This excellent agreement between measured surfaces of seafloor textures identified both in drone and AUV imagery demonstrates that these seafloor patterns (WHPs, Posidonia, DHPs) are equivalent, and that drone imagery can be used for accurate mapping regionally. At the same time, AUV groundtruthing reveals other seafloor textures not imaged by the drone (Bioturbation, Cymodocea patches). AUV imagery also provides detailed maps where sampling and temperature measurements can be precisely located relative to seafloor structures, therefore enabling their interpretation.

\subsection{Subseafloor temperature patterns}

Based on mapping at Paleochori Bay, we assign a geological setting for each temperature measurement using 6 seafloor categories, as reported in Tables 5, S1 and S2, and in Figure 10 (see their description in Section 3.2). Temperature measurements in Paleochori were made at different subseafloor depths, depending on probe rod lengths. As there are significant temperature gradients throughout the study area (see Tables 5, S1, and S2, Figure 10), we provide temperatures at $35 \mathrm{~cm}$ subseafloor, to minimize any depth bias in spatial temperature patterns, facilitating their interpretation (see methods section, and full data, including temperature gradients, in Tables S1 and S2). We first present results from a study site displaying a polygonal 
hydrothermal pattern (Hexagon study site, Figure 11), and then results from other measurements throughout Paleochori Bay (Figure 12).

\subsubsection{Hexagon study site}

To establish the association between the different seafloor types and subseafloor thermal regimes, we conducted a focus study on an area at Paleochori that displays a clear polygonal organization of hydrothermal outflow (Figure 11). In particular, we selected a hexagonal structure with white hydrothermal seafloor at its edges, referred to as the "Hexagon" from here on. We measured temperatures along six profiles, crossing the edges of this hexagon, gathering measurements at WHPs, transition from WHPs to BT (WHPs/BT), Bioturbation (BT), and Non-hydrothermalized Sand (NS) (Figures 10 and 11).

As shown by the blue symbols in Figure 10a, the highest temperatures are recorded below the WHPs, at the edges of the Hexagon $\left(\sim 67^{\circ} \mathrm{C}\right.$ in average, maximum temperatures of $\left.\sim 73{ }^{\circ} \mathrm{C}\right)$, with a progressive and gradual radial decrease towards the Non-hydrothermalized Sand, in adjacent polygons and at the center of the hexagon. These $N S$ areas display seawater-like temperatures (21.82 ${ }^{\circ} \mathrm{C}$ in average), reaching up to $\sim 33{ }^{\circ} \mathrm{C}$ in close proximity to the transition towards the bioturbated terrain. In addition to these lateral thermal gradients, we document a limited data spread of $<\sim 20^{\circ} \mathrm{C}$ (standards deviations of $\sim 5.25-4.10^{\circ} \mathrm{C}$ ). Subseafloor temperatures thus show consistent lateral variations around the edges of this polygon, that are well-correlated with seafloor types.

The temperature sensor set 'Poseidon' was positioned at the center of each profile, thus providing six vertical temperature gradients at the Hexagon (Figure 10b, Table S1). The lowest gradient of the area is measured in bioturbated $(B T)$ seafloor $\left(50.85^{\circ} \mathrm{C} / \mathrm{m}\right)$, while the WHPS display the 
maximum gradient $\left(94{ }^{\circ} \mathrm{C} / \mathrm{m}\right)$. These thermal gradients are completed by values acquired over a broader study area (Paleochori Bay), as discussed below.

\subsubsection{Paleochori Bay}

While polygonal patterns are common at Milos (e.g. Paleochori or Spathi Bay), we studied other areas of interest that show structures with varying sizes, shapes, textures, compositions and that lack polygonal organization (Figure 12). Field work at several sites throughout Paleochori allows us to test if the subseafloor thermal regimes at the Hexagon and elsewhere show similar patterns or if the differences in outflow geometry, in addition to the seafloor texture, also control subseafloor temperatures, and result in different thermal regimes for similar textures. We thus acquired subseafloor temperature values at White Hydrothermal Patches (WHPs), Bioturbations (BT), Normal Sand (NS), Hydrothermal Sand (HS) and Fluids (FL). We note that these last two categories correspond to measurements at or near actively venting sites (gas, fluids, or both), where small-scale variations in seafloor nature and texture can only be identified by in situ observations, and are hence not documented on the AUV or drone photomosaics.

As in the Hexagon, we document the same lateral thermal variation from WHPS to NS (Figure $10 \mathrm{a}$, red symbols). Indeed, the mean temperature at $35 \mathrm{~cm}$ subseafloor and under WHPs is $\sim 65^{\circ} \mathrm{C}$ ( $\sim 67{ }^{\circ} \mathrm{C}$ in average at the Hexagon). Under $N S$ terrain these temperatures tend to decrease, with maximum temperatures of $\sim 32{ }^{\circ} \mathrm{C}$, and in average near-seawater temperatures $\left(\sim 28{ }^{\circ} \mathrm{C}\right.$ vs. $21^{\circ} \mathrm{C}$ at the Hexagon). The bioturbated terrain and the transitions to both WHPS and to NS terrain display intermediate values.

Vertical temperature gradients were measured at every site, using one or several sets of instruments ('Poseidon', 'Set 1' and 'Set 2', Figure 10b). Gradients for WHPS, BT and NS are all 
$<100{ }^{\circ} \mathrm{C} / \mathrm{m}$, as seen on the hexagon, and while the data is sparse and shows significant variability, it suggests a decrease in observed thermal gradient from WHPs towards NS terrain, mimicking the lateral variations in subseafloor temperature.

In addition to seafloor types observed in the photomosaics, we measured temperatures at hydrothermalized sediments, and around gas and fluid vent sites ( $H S$ and $F L$, Table 5 and Figure 10). These sites show extreme variability in both the temperature ranges (up to $100{ }^{\circ} \mathrm{C}$ and $>150{ }^{\circ} \mathrm{C}$ for $H S$ and $F L$ respectively, Figure 10a) and the associated thermal gradients (up to $150{ }^{\circ} \mathrm{C} / \mathrm{m}$ and $>400{ }^{\circ} \mathrm{C} / \mathrm{m}$, respectively, Figure $10 \mathrm{~b}$ ). While most of the measurements in $H S$ seafloor throughout Paleochori bay show gradients $<100{ }^{\circ} \mathrm{C} / \mathrm{m}$, we identify a single site with $>100{ }^{\circ} \mathrm{C} / \mathrm{m}$ (Figure 10b). While we cannot establish a direct comparison with the results of Khimasia et al. (2021), we have calculated both the gradient and the subseafloor temperature based on their data (Supplementary Table 2 in Khimasia et al., 2021), and selecting the sites that show a temperature increase with depth. We observe that a) the subseafloor temperatures obtained in this study, and reported at $35 \mathrm{~cm}$ subseafloor, range from $\sim 25$ to $\sim 100{ }^{\circ} \mathrm{C}$, with a single value exceeding $100{ }^{\circ} \mathrm{C}$, and b) that the gradients are typically $<100{ }^{\circ} \mathrm{C} / \mathrm{m}$, with only two sites reporting gradients $>100{ }^{\circ} \mathrm{C} / \mathrm{m}$. These values are thus in good agreement with our results, and suggest that the associations that we observe between seafloor patterns and subseafloor temperature can be generalized to the study area.

\section{Discussion}

\subsection{Distribution and quantification of hydrothermal activity}

The interpreted seafloor patterns, derived from drone imagery and ground-truthed by AUV photomosaics and in situ observations (Figure 2) characterize in detail the organization of 
hydrothermal outflow through the seafloor. In particular, we document actively venting areas, their regional distribution through the study area (Figure 1), and characterize in detail their nature and geometry.

Areas of active hydrothermal outflow are highlighted by White Hydrothermal Patches (WHPs), which are associated with elevated subseafloor temperatures (reaching up to $\sim 75^{\circ} \mathrm{C}$ ). Mapped both on drone and AUV photomosaics, WHPs are necessarily associated with active hydrothermal flow of high-temperature fluids through the seafloor, required to sustain the white mineral precipitates and/or bacterial mats. Our mapping documents two clearly different organizations of the outflow, that we attribute to different modes in the subseafloor fluid circulation. First, some areas display clear polygonal patterns (e.g., Figure 8a, Figure 11), with spatial scales that vary from $\sim 5 \mathrm{~m}$ to $\sim 50 \mathrm{~m}$. This type of organization develops in sandy, mobile seafloor, that blankets most of the seafloor at Paleochori, Spathi and Agia Kyriaki bays. The center of these polygons corresponds systematically to sediment showing no hydrothermal signature, with clear and pervasive ripple marks (Figure 4, Figure S4). This type of outflow organization is clearly visible in Paleochori East (Figure 8a) and in Spathi Bay, although with smaller polygons $(<20 \mathrm{~m}$, see Figure $8 \mathrm{c})$. In addition to the well-defined and continuous polygonal patterns, numerous isolated patches throughout Paleochori show alignments defining discontinuous polygon edges. This polygonal organization of hydrothermal outflow, together with the systematic temperature patterns observed across them (Figure 10), clearly point to a well-structured subseafloor flow organization.

These seafloor geometries are reminiscent of polygonal patterns recognized during fluid convection in sandy porous media heated from below (e.g., Nield and Bejan, 2006). While polygonal convection in the laboratory can result both in upwelling and downwelling at polygon 
edges depending on experimental conditions, our temperature patterns suggest upwelling below WHPs, while cell centers are downwelling zones and hence at seawater temperatures. The geometry and size of the cells depend on both the permeability and thickness of the porous layer, and on hydrothermal fluids properties. However, to date, we lack constraints on the physical properties of the sediments in the area (porosity and permeability, in addition to thermal conductivity), and on the thickness of the sediment layer at Paleochori and other bays, likely underlain by rocky basement.

WHPS are also found as broad and extensive patches, often with a gradual transition to sedimented seafloor, and without showing a clear geometric organization (e.g. limits, internal structure). We interpret these patches as evidence of widespread and diffuse outflow through the seafloor, lacking the focusing inferred for areas displaying polygonal patterns. Hence, the variations in the density of these patches (qualitatively classified as High, Medium, and Low density WHPs, see Figure 4), may correspond to spatial changes in either the hydrothermal fluid mass flux, temperature variations, or both, that are gradual and distributed. Our temperature measurements within these WHPs are not dense enough to verify this, and additional studies with in situ measurements are required instead.

In addition to the white reflective areas, drone imagery allows us to identify and map darker areas (DHPs) and lineations, with geometries and patterns that are similar to those of the WHPs. AUV imagery shows that these darker seafloor textures are of several possible origins. For example, the dark patches (DHPS) and lineations identified at Spathi Bay are sandy and seem to be closely associated with the WHPS spatially, in some instances appearing on their continuity. Similar sharp or more transitional change from white areas toward darker material (brown, green brown or gray) have been described (Aliani et al., 1998b, Sievert et al., 1999, Bayraktarov et al., 2013) 
showing sometimes complex patterns (Wenzhöfer et al., 2000). These transitional areas before normal Non-hydrothermalized Sand are interpreted as change in bacterial population and type of precipitate containing manganese and iron oxide (Sievert et al., 1999; Wenzhöfer et al., 2000; Callac et al., 2017). In other areas these dark patches and lineations appear in zones that do not display any WHPS. While we did not investigate these areas systematically with temperature sensor deployments, some of the measurements indicate elevated temperatures (up to $95{ }^{\circ} \mathrm{C}$ at 35 $\mathrm{cm}$, see Table S1 and Table S2) suggesting that at least some of these zones are also active. This is also confirmed by recent in situ studies over a hydrothermal patch at Spathi Bay (Callac et al., 2017), suggesting that these are due to goethite precipitates. In situ observations also display seafloor areas with ochre hydrothermal precipitates (see Section 2), that may appear as dark seafloor in both AUV and drone imagery. Hence, such dark patterns may correspond to fossil, inactive areas of hydrothermal outflow, or to active areas with hydrothermal precipitates yielding a darker seafloor pattern, often adjacent to bacterial mats or white hydrothermal precipitates (e.g., Callac et al., 2017). These types of seafloor patterns, with both visually white seafloor areas and darker seafloor structures, have been identified in deep-sea hydrothermal systems, and interpreted as active and inactive hydrothermal outflow areas respectively (e.g., Lucky Strike, Barreyre et al., 2012).

AUV imagery also reveals dark patches and lineations corresponding to the seagrass Cymodocea nodosa, at both Paleochori West and East (Figure 8). While we have limited AUV coverage, our observations suggest that these are closely associated with the WHPs, often surrounding them (e.g., Figure $8 \mathrm{a}$ and $\mathrm{b}$ ). These observations are consistent with the spatial associations discussed by Aliani et al. (1998b) between the distribution of seagrass and their link to hydrothermal activity. 
To discriminate between a biological origin (seagrass, or debris of seagrass, Figure S5) or a hydrothermal one (active or inactive hydrothermal outflow zones and associated recent or altered precipitates), and in the absence of direct observations or AUV surveys, drone photomosaics should be acquired at different times, as debris are mobile, and thus likely associated with transient patches. In contrast, we speculate that dark areas of hydrothermal origin may be more persistent over time, as suggested by the preserved geometry of the hydrothermal outflow in the area over several years, documented by the imaging of WHPs through satellite imagery (Martelat et al., 2020), and by their association to white patches (Callac et al., 2017).

Quantitative comparisons of seafloor types visible on both drone and AUV photomosaics show that surface estimates are equivalent using both image datasets (Figure 9, Table 4). Minor differences observed in our surface estimates may have multiple causes. First, we may document temporal, local changes between the acquisition of the drone and AUV imagery. Second, imaging conditions differ significantly between the AUV (near-seafloor acquisition, with images acquired a few meters above seafloor), and the drone (imaging through the full water column). Drone imagery is strongly influenced by several external factors, such as sun illumination angle, sea surface reflections or water turbidity (e.g., Martelat et al., 2020). AUV imagery may also be affected by flickering (light refraction by surface waves), among others. Finally, drone imagery is acquired through a water column that varies in thickness from near-zero (shore) to up to $15-20 \mathrm{~m}$ in the deepest parts. These factors may in part explain the differences observed between a prior survey (Khimasia et al., 2020), owing to the combination of differences in imaging conditions and temporal changes between the drone surveys. Hence, with drone data we expect a loss of resolution and definition that increases away from the shore. Despite these factors, our 
comparison indicates consistency across datasets, and that we can confidently use broader drone imagery and its interpretation to extrapolate local AUV observations.

\subsection{Links between seafloor patterns and subseafloor temperatures}

Subseafloor temperature measurements display spatial variations that we can directly link to seafloor hydrothermal patterns, and thus provide information on subseafloor organization of hydrothermal flow. Subseafloor temperatures and gradients reported in other areas of Paleochori (Khimasia et al., 2021), while they cannot be directly correlated to specific seafloor textures in our study, are consistent with our results, and suggest that these lateral temperature gradients, at scales of a few to $\sim 10 \mathrm{~m}$, are well established and consistent throughout. Gradients are controlled by the temperature decrease from the WHPS (average of $\sim 67{ }^{\circ} \mathrm{C}$ and reaching $\sim 75{ }^{\circ} \mathrm{C}$ at some sites) to the sediments lacking hydrothermal alteration, $N S$ (temperatures between those of seawater and $\sim 30{ }^{\circ} \mathrm{C}$ ), with transitional values in bioturbated areas, $B T$, that bound the $W H P S$ (Figure 10). These temperature gradients away from individual WHPs, documented here at the "hexagon" and at other sites around Paleochori Bay (Figure 11, Figure 12), are also described at Paleochori Bay by prior studies, at subseafloor depths of up to $10 \mathrm{~cm}$, and with maximum measured temperatures of $\sim 100{ }^{\circ} \mathrm{C}$ instead (e.g. Figure 3 in Wenzhöfer et al., 2000). Such significant lateral gradients over short spatial scales require active fluid circulation, with focused hydrothermal flow and discharge at the WHPs seafloor, and a possible recharge at nonhydrothermalized sediments, either at the center of polygonal structures, or around the isolated and disconnected patches elsewhere in Paleochori. We anticipate that this fluid flow organization may be common at sedimented shallow-water systems showing polygonal patterns, such as Spathi and Voudia Bays in Milos, or Vulcano in Italy (Martelat et al., 2020), even though no temperature data are available from these sites. 
The hydrothermal patterns visible in AUV and drone imagery and described above are associated with areas showing gas venting (instrumented sites indicated as FL in Table S2), or sands showing hydrothermal deposits of colors other than white and only identified with in situ scuba diver observations (areas categorized as $H S$ ). Clearly associated with hydrothermal outflow, these hydrothermalized deposits can only be identified by in situ divers and are only partially imaged by the drone and AUV. Subseafloor temperatures at these sites display significant variations (ranging from $\sim 30{ }^{\circ} \mathrm{C}$ to $\sim 95^{\circ} \mathrm{C}$ ) and cannot be correlated with the horizontal thermal gradients described above. The temperature measurements assigned to the 'Fluids' category regroup measurements in both degassing outflow and brine seeps. Focused venting likely results in temperature variations at scales similar to the venting sites (a few $\mathrm{cm}$ to $<1 \mathrm{~m}$ ), and may explain the extreme variability observed in our data. To better understand these structures, subseafloor temperatures should be acquired in a systematic manner with dense sampling to characterize and constrain the spatial variations at scales of $<1 \mathrm{~m}$.

Overall, the thermal gradients in the shallow subseafloor are extremely elevated, often above $100{ }^{\circ} \mathrm{C} / \mathrm{m}$ below the WHPs. These values point to a thin conductive layer (up to $1-2 \mathrm{~m}$ ) that corresponds to the cap of sediment saturated with hydrothermal fluids and/or gases at $\sim 100{ }^{\circ} \mathrm{C}$ below WHPS, either in zones that are narrow and focused (e.g., small patches or edges of polygonal patterns), or over broader areas underlying the large patches instead. Furthermore these gradients suggest efficient conductive cooling near-seafloor of the upwelling high-temperature fluids, a mixture with cool seawater, or a combination of both. This is consistent with a porous flow of hydrothermal fluids at very slow speeds, with no visual expression at the seafloor, where there is conduction in the shallow subseafloor overimposed on an advective system. Figure 13 shows a schematic representation of subseafloor hydrothermal circulation, depicting the lateral 
thermal gradients, with local, focused gas discharge to the seafloor, that is decoupled from the surrounding hydrothermal flow at shallow, near-seafloor levels.

\subsection{Hydrothermal patterns impact local ecosystems}

Submarine hydrothermal outflow sustains chemosynthetic ecosystems, such as microbial mats (e.g., Jannasch and Wirsen, 1981; Barreyre et al., 2012), and associated macrofauna. At Milos, AUV imagery reveals a strong hydrothermal control on macrofauna distribution. As seen on the AUV photomosaics, bioturbation is abundant, clearly recognizable in the imagery, and attributed to the burrowing activity of the mud shrimp Callianassa truncata (Ziebis et al., 1996; Robinson et al., 1997). This burrowing continuously remobilizes sediment, obliterating the ripple marks that develop at the seafloor. We identify two different settings for this bioturbation. The most common one corresponds to bands up to a few meters wide that frame WHPs, and is seen in almost all of the polygons and patches imaged by AUV (Figures 8 and 13). The second one corresponds to broad areas extending over several tens of square meters that are not adjacent to WHPS. Associations between the distribution of hydrothermal activity and other type of macrofauna have also been proposed, but could not be verified with our AUV mapping. This is the case for sessile epibenthos at Milos around vents in rocky areas (Bianchi et al., 2011), and for fish and crabs (Aliani et al., 1998b; Gamenick et al., 1998).

Our subseafloor temperature measurements suggest that bioturbated zones may map a thermally optimal habitat for C. truncata, often at the transition between the WHPs $\left(\sim 70{ }^{\circ} \mathrm{C}\right)$ and the sedimented seafloor with no hydrothermal activity $\left(N S, 25^{\circ} \mathrm{C}\right)$. In addition, the nearby bacterial mats may provide a source of nutrient and carbon for the shrimps, as proposed for other organisms (e.g., Bianchi et al., 2011). The bioturbation zones found in areas away from WHPS 
may indicate diffuse outflow insufficient to support bacterial mat growth. There is to our knowledge no description of the upper thermal tolerance of $C$. truncata. However, it seems unlikely that it can survive the temperatures higher than $50{ }^{\circ} \mathrm{C}$ found in WHPs, suggesting a temperature threshold between the bioturbated areas and the WHPs. The temporal stability of the hydrothermal system is well documented by satellite imagery (Martelat et al., 2020), and is also supported by a qualitative comparison of our drone data with that from an earlier survey (Khimasia et al., 2020) that shows only minor and local differences in the distribution of hydrothermal patches and structures. However, new AUV surveys will be critical to verify if the zones burrowed by Callianassa truncata are persistent in the long term, or if these ecosystems show significant spatial variations over time that may be linked to changes in subseafloor temperature.

We also observe that Posidonia oceanica only grows south and outside of Paleochori Bay, while the seagrass Cymodocea nodosa is found in the vicinity of the hydrothermal vents and around patches. This is consistent with the proposed interpretation by Aliani et al. (1998b) suggesting that $C$. nodosa has a higher thermal tolerance than $P$. oceanica, and that both are absent in areas with elevated subseafloor temperatures (Aliani et al., 1998).

Bacterial mats at the seafloor are the most visible ecosystem, and the one used here to infer the geometry and distribution of active hydrothermal activity. The microbiology of Paleochori Bay has been the focus of several studies in the past decades (e.g. Brinkhoff et al., 1999, Giovannelli et al., 2013, Price et al., 2013). These studies have shown the presence of multiple microbes involved in the sulfur cycle. However, most of these studies used now outdated methods, and no investigation using next-generation sequencing technology has been published yet. As a follow up of this study and the fieldwork conducted in 2019 , there is a study in progress providing a 
detailed description of the microbial communities in relation to the different subseafloor thermal regimes and seafloor patterns described here.

Photomosaics from the Milos hydrothermal site document the distribution of ecosystems associated with hydrothermal circulation, and may be used for quantitative studies. For example, the areas bioturbated by $C$. truncata, mapped in AUV surveys, cover a surface that is commeasurable to that of WHPS at three different locations (Table 4). We thus expect that this terrain and the associated ecosystem is widespread throughout our study area, covering significant portions of the seafloor and surrounding WHPS areas identified by our drone mapping. Hence, detailed studies of hydrothermal ecosystems, including their distribution, nature, and quantification, require systematic seafloor mapping with underwater imagery (i.e. AUVs) in addition to in situ observations (e.g., scuba divers) that cannot be used for quantitative studies. Aerial surveys do provide a regional view of these systems, including predictive subseafloor temperature patterns and associated overall hydrothermal outflow, but fail to capture the details of these structures (e.g., certain macrofauna ecosystems, zones of focused fluid and gas venting, etc), in addition to being limited to near-shore environments ( $<20 \mathrm{~m}$ water depth).

\subsection{Perspectives on heat fluxes}

The shallow water hydrothermal system of Milos is complex, extending over a significant area to depths well below those studied here, and displaying different modes of hydrothermal outflow. Systematic mapping and quantification of these systems is needed to estimate in fine associated fluxes (mass, heat, chemical output). While we focused our study on systematic seafloor imaging coupled with subseafloor temperature measurements, the results presented here provide the background for future studies and fieldwork to constrain the heat flux of this system. The total 
heat flux of a hydrothermal system such as Milos is partitioned between conductive and advective fluxes (Figure 13). Pure conductive heat fluxes can be enhanced by the proximity of a heat source, and at Milos we anticipate a subseafloor saturated in high-temperature fluids at a shallow level, with a thin conductive layer, as required by the significant thermal gradients observed. Advective fluxes are partitioned into diffuse and focused flow (Figure 13), with both fluid and gas venting.

The WHPs mapped likely correspond to diffuse fluid percolation at small spatial scales $(<1 \mathrm{~m})$, while the focused flow is observed at gas venting sites and brine pools, where higher temperatures with extreme variability are observed (Figure 10). Fluxes associated with focused flow are difficult to evaluate, as the number of venting sites, their distribution throughout the study area, and the associated characteristics (temperature, mass flux, outflow velocity) are difficult to estimate systematically, as discussed below.

Heat flux from diffuse hydrothermal flow has been estimated in deep-ocean systems (e.g. Barreyre et al., 2012), and is calculated from:

$$
Q=\Delta T * \rho * v * C p * S
$$

where $\Delta T$ is the temperature difference between outflow temperature $\left(38^{\circ} \mathrm{C}\right)$ and ambient seawater $\left(24{ }^{\circ} \mathrm{C}\right), \rho$ is the density of seawater, $v$ is the flow velocity $(\mathrm{m} / \mathrm{s}), C p$ is the specific heat of the diffuse fluid and $\mathrm{S}$ is the considered area of diffuse outflow $\left(\mathrm{m}^{2}\right)$. Here we can estimate $\Delta T$ from the temperature dataset and $\mathrm{S}$ from the photomosaics (Table 2), while assuming values for $\rho$

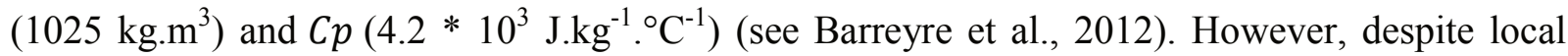
studies of gas flow rates (e.g. Botz et al., 1996; Megalovasilis, 2020), we lack a precise and consistent estimate of the fluids velocity, their composition and nature (and hence density) and 
their variability, that could be extrapolated regionally. To obtain a flux estimate, we assume a diffuse velocity flow through the WHPs between a minimum and a maximum of 1 and $5 \mathrm{~mm} / \mathrm{s}$ respectively, that is based on diffuse flow studies through bacterial mats elsewhere (Sarrazin et al., 2009; Barreyre et al., 2012). Table 6 provides values for each study area and WHPs type. Focusing on Paleochori Bay, the best studied area, our preliminary diffuse heat flux estimates vary between $\sim 2350$ and $11760 \mathrm{MW}$ (Table 6). We note that Khimasia et al. (2021) report a mass flux of $\sim 11300 \pm 1100 \mathrm{~m} 3 /$ day, based on the extrapolation of vertical velocity of fluids based on a model of advection and cooling from subseafloor temperature measurements that we cannot colocate systematically with hydrothermal patterns at the seafloor, which yield values of 0.4-0.95 $\mathrm{m} /$ day (Fig. 11 in Khimasia et al., 2021), or .004-.01 mm/s. With these values, the advective heat flux would be negligible (a few tens of MW or less). This demonstrates that additional studies are required to better constrain fluid flow values in a systematic manner, and taking into account seafloor patterns of hydrothermal outflow.

Heat flux from focused flow contributes further to the advective fluxes of the area, and depends on the fluid outflow temperature, the mass flux, and the abundance of venting sites (spatial distribution, size and mass fluxes). Constraints on this advective flux thus require a systematic mapping of the venting sites (or a representative subset), coupled to flux and temperature measurements and fluid sampling. For example, Figure $8 \mathrm{a}$ shows a detail of Paleochori displaying polygonal structures imaged by the AUV. Careful examination of the photomosaics allows us to identify gas venting sites as bubble trails emanating from the seafloor. When gas flow rate is low, trails are not captured, as individual bubbles imaged in the water column cannot be traced to a seafloor source. In situ observations by divers are limited to a few sites, and are insufficient to establish a quantitative map on distribution and abundance of gas and fluid venting 
sites, nor to determine any temporal variability (e.g., tidal). Finally, our preliminary observations do not show a clear spatial association between the position of venting sites and seafloor structures mapped in photomosaics, as gas venting is observed in areas of sedimented seafloor $(N S)$, zones of bioturbation, and in WHPs. While temperature measurements at a few gas venting sites are elevated (close to $\sim 100^{\circ} \mathrm{C}$ ), and with highly variable gradients (Table 5 and Figure 10), we cannot relate gas outflows to the systematic patterns of subseafloor temperature associated with bacterial mats.

Our observations and results suggest that in the shallow subseafloor, and at small spatial scales (a few 10s of $\mathrm{m}$ or less) gas flow is decoupled from diffuse fluid flow, and hence seafloor patterns cannot be used to predict or quantify gas outflow location and density. For example, Botz et al. (1996) report surface gas flow rates of up to $\sim 200 \mathrm{ml} / \mathrm{m}^{2} / \mathrm{min}$ while recently Megalovasilis (2020) reports gas and fluid flow rates at individual sites ranging from 4.5 to 63 1/h (gas) and 25 to 92 1/h (water), with temperatures ranging between $30{ }^{\circ} \mathrm{C}$ and $110{ }^{\circ} \mathrm{C}$. We conducted an experiment at Paleochori at two sites, and obtained two gas flow rates values of $18 \mathrm{l} / \mathrm{h}$ and $360 \mathrm{l} / \mathrm{h}$, the latter significantly higher than the values reported by Megalovasilis (2020). Lacking a clear understanding of the density, distribution, flow rate, and nature (fluid and gas composition) of focused gas and fluid outflow (vents), we cannot extrapolate of these values regionally to infer well constrained fluxes. To evaluate qualitatively the relative importance of diffuse vs. focused heat flux, we use values provided by Megalovasilis (2020) for $\sim 50$ vents, with average outflow temperature of $93{ }^{\circ} \mathrm{C}\left(\Delta \mathrm{T}=69^{\circ} \mathrm{C}\right)$ and average flow rate of $\sim 58 \mathrm{l} / \mathrm{h}$. These surveyed sites yield a combined heat flux of $\sim 0.2 \mathrm{MW}$, and thus a very small fraction of the diffuse heat flow estimate ( 2350 - 11760 MW, Table 6). Heat flux associated with the gas outflow is negligible as the heat capacity of gases is two orders of magnitude lower than that of seawater. 
As thermal gradients are significant in the shallow seafloor, part of the heat loss is also conductive, associated to an enhanced and thin conductive layer. With a mean thermal gradient of $\sim 64{ }^{\circ} \mathrm{C} \mathrm{m}^{-1}$ for the WHPs (Table 5), and a typical thermal conductivity for sediments $\left(1.7 \mathrm{~W} . \mathrm{m}^{-}\right.$ ${ }^{1}{ }^{\circ} \mathrm{C}^{-1}$ ), the conductive heat flux through all the WHPs at Paleochori would correspond to $\sim 4 \mathrm{MW}$ $\left(109 \mathrm{~W} / \mathrm{m}^{2}\right)$, which is significantly lower than our diffuse heat flow estimates.

While poorly constrained, these heat fluxes provide a first-order view into heat flux partitioning at Milos. Prior studies at deep-sea hydrothermal sites indicate that diffuse flow may account for at least $\sim 50 \%$ and up to more than $90 \%$ (e.g., Veirs et al., 2006; Ramondenc et al., 2006; Barreyre et al., 2012; Escartin et al., 2015). The preliminary heat flux estimates presented here lack additional constraints, such as temperature measurements, knowledge of physical properties of sediments (e.g., conductivity of sediments, nature and density of fluids, outflow velocities), or chemical indicators, such as such as patterns of Rd concentration in hydrothermal fluids and in the water column (e.g., Rudnicki and Elderfield, 1992). As both the heat fluxes associated with focused flow (limited to the vents investigated by Megalovasilis, 2020) and the conductive heat flow are only a fraction of the lowest estimate of diffuse heat flux, we postulate that heat loss at the Milos shallow water hydrothermal site is dominated by diffuse flow. This partition may also prevail at deeper water depths that have not been systematically surveyed yet (Nomikou et al., 2013). As we have systematically mapped only to water depths of $\sim 20 \mathrm{~m}$, and with hydrothermal activity to depths of $500 \mathrm{~m}$ or more, we anticipate that this is one of the most extensive and significant underwater hydrothermal systems identified to date. For comparison, heat fluxes at hydrothermal systems along the Mid-Atlantic Ridge such as Lucky Strike ( 1000 MW, Barreyre et al., 2012; Escartin et al., 2015) or Rainbow (1000-5000 MW, Thurnherr and Richards, 2001) 
are within the range of diffuse flow estimates at Paleochori Bay at depths $<20 \mathrm{~m}$, which is a small fraction of the whole Milos system (additional bays and hydrothermal activity at depths $>20 \mathrm{~m}$ ).

To document the full extent of this hydrothermal system and fully evaluate the fluxes, we require systematic mapping and surveying coupled to sampling, and conducted with underwater robots. This mapping will also allow us to establish the links to ecosystems, and the controls on outflow geometry. Future studies will seek to constrain the thickness of the permeable layer hosting this fluid flow organization with subseafloor geophysical surveys, acoustic mapping of the water column to systematically map gas plumes, in addition to physical properties of sediments (thermal conductivity, porosity, permeability). 


\section{Conclusions}

Drone imagery, ground-truthed by AUV photomosaics, provides a detailed geological context for in situ samples, measurements and observations. With these data and observations we establish a regional overview of the shallow-water hydrothermal system along the SE coast of Milos and to depths of $\sim 20 \mathrm{~m}$. We constrain not only the organization of its hydrothermal outflow, but also its subseafloor flow, the effects of this hydrothermal activity on both macrofauna and microbial ecosystems, and discuss the magnitude and partition of associated heat fluxes.

Photomosaics are interpreted to constrain the distribution and quantification of hydrothermal activity. At Milos, bacterial mats and hydrothermal mineral precipitates show up as White Hydrothermal Patches with elevated subseafloor temperatures $\left(>50{ }^{\circ} \mathrm{C}\right.$ and up to $\left.75^{\circ} \mathrm{C}\right)$ that are organized in polygonal patterns, isolated patches, or in more broad and dispersed areas. These patches are systematically bound by bioturbated areas, with subseafloor temperatures of $(\sim 30$ $40^{\circ} \mathrm{C}$ ), that transition to sandy seafloor lacking any hydrothermal signature, and with subseafloor temperatures close to those of seawater (typically $<32{ }^{\circ} \mathrm{C}$ ). These gradients both in seafloor texture and subseafloor temperature document the position of persistent hydrothermal outflow, that is diffuse and associated with low outflow velocities through the seafloor.

This hydrothermal activity, and its organization, impacts both the distribution of bacterial mats at the seafloor, and of macrofauna. Indeed, the lateral thermal gradients are exploited by a burrowing shrimp, Callianassa truncata, as this narrow band of seafloor is an optimal environment thermally close to white hydrothermal areas, a likely source of nutrients. The burrowing activity of this shrimp continuously reshapes the seafloor, obliterating its otherwise 
rippled morphology, forming bioturbation, a seafloor texture that can be identified in nearseafloor AUV imagery.

Hence, our results show that drone photomosaics can be used to link seafloor hydrothermal patterns and subseafloor temperature data in order to predict subseafloor hydrothermal circulation regionally, to water depths of $\sim 20-30 \mathrm{~m}$. AUV imagery provides visual ground-truthing that is critical to identify structures and patterns that cannot be observed in aerial images, hindered by water column turbidity and attenuation and surface illumination artifacts such as sea surface reflections. This AUV imagery also allow us to establish the associations between ecosystems and hydrothermal flow, and to predict their distribution regionally based on drone imagery. This systematic mapping of the shallow-water hydrothermal system of Milos is also a first step to evaluate the thermal, mass, and chemical fluxes in the area and to evaluate the controls of hydrothermalism on microbial communities subseafloor, both spatially and in depth. Our preliminary analysis to establish heat fluxes also suggest that diffuse flow accounts for a significant portion of the total heat output in the surveyed area, but heat and mass flux quantification requires future dedicated experiments, with adequate constraints on the physical properties of the sediments hosting the hydrothermal flow. We postulate that Milos is one of the most active underwater hydrothermal systems on Earth, based on the fluxes that we estimate are associated with its shallow, near-shore portion, and its extension to deep waters $(>500 \mathrm{~m})$ and throughout the island, in areas yet unsurveyed. 


\section{Acknowledgments}

We acknowledge the assistance of Cedric Hamelin during field operation in September 2019. This project was partially funded by INSU-CNRS Tellus and Syster Projects to JE (2016) and JEM (2018), and by the RAMONES project (EU H2020 FET 101017808) to JE. Additional support was provided by internal funds from ENS, IPGP, U. of Lyon, and U. of Bergen. We also benefitted from the comments of two anonymous reviewers, that helped us clarify and improve this manuscript.

\section{Data Availability Statement}

The drone photomosaics used in this article can be found at https://doi.org/10.17882/77670, an open-source online data repository hosted at SEANOE (Martelat et al., 2019).

The AUV photomosaics used in this article can be found at https://doi.org/10.17882/77669, an open-source online data repository hosted at SEANOE (Puzenat et al., 2019a).

The shapefiles for AUV and Drone photomosaic interpretations and instrument locations used in this article can be found at https://doi.org/10.17882/77668, an open-source online data repository hosted at SEANOE (Puzenat et al., 2019b).

The temperature records used in this article can be found at https://doi.org/10.17882/77656, an open-source online data repository hosted at SEANOE (Puzenat et al., 2019c). 


\section{$9 \quad$ Figures captions}

Figure 1. (A) Location map showing drone and AUV coverage. Orange square locates Figures 4e, 4f. Yellow square locates Figures 4a, 4b. Green squares locates Figures 4c, 4d. Red square locates area studied on Figure 2. (B) Zoom of Figure 1a on Paleochori Bay. Red dots indicate temperature measurements. Yellow square locates the 'hexagon' (see section 4.2.1, Figure 11). C) Simplified map of the Aegean Sea showing the location of Milos. Modified from Valsami-Jones et al., (2005). D) Simplified map of Milos island, locating the studied bays. Rectangles in (A) and (B) indicate the location of other figures as indicated by the labels. This and follow-up maps show UTM coordinates in m (UTM zone $35 \mathrm{~N}$ ).

Figure 2. Example of a hydrothermally active area at Paleochori Bay, with the same hydrothermal patch shown in all images (red outline), in (A) Multispectral WorldView 2 image from July 2013 provided by the Digital Globe Foundation (see Martelat et al., 2020), (B) Drone photomosaic from June 2019, (C) AUV Sparus II seafloor photomosaic from June 2019, (D) Hand-held underwater image by scuba divers from September 2019. The black dot locates one temperature measurement. Location of images is shown in Figure 1.

Figure 3. Details of the uninterpreted (left) and interpreted (right) drone photomosaics for Spathi Bay (A and B), Paleochori Bay (C and D), and Agia Kyriaki (E and F). Location of areas is shown in Figure 1.

Figure 4. Details of the uninterpreted (top) and interpreted (bottom) AUV photomosaics for Paleochori Bay (A through D), and Spathi Bay (E and F), showing the different seafloor textures identified and their spatial associations. Location of the 3 sites are shown in Figure 1. 
Figure 5. (A) Temperature time record for the bottom sensor of the Poseidon instrument set (blue line, Dive 7), showing several short-term deployments (deployment names correspond to those reported in Table S2). Red portions of the curve at each deployment correspond to the data used to calculate average temperatures reported in Table S2. The type of seafloor at each site is also indicated attached to the deployment name (WHPs: White Hydrothermal Patches. BT: Bioturbation. HS: Hydrothermalized Sand). The records show clearly the probe insertion at the seafloor, followed by a sudden increase of temperature, and the extraction by sudden drops. (B) and (C) show the field image of the Poseidon instrument installed at the seafloor, in bioturbated seafloor (B) and in a white hydrothermal patch (C), showing that these correspond to a thin layer (bacterial mat, hydrothermal precipitates) covering the otherwise sandy seafloor.

Figure 6. (A) Set of NKE temperature probes ("Poseidon"), deployed at the seafloor (scuba diver hands for scale). (B) "Poseidon" temperature records for one of the deployments (Dive 6 Deployment 3 - Patch 2, see Table S2). (C) Average temperatures (red circles) vs. depth for the temperature records in (B), and calculated thermal gradient fitted to the data (dashed line). The insertion and the extraction of the sensor set are clearly shown by the increase and decrease in temperature, respectively.

Figure 7. Drone photomosaics (background) with interpreted seafloor textures and features from our study areas of (A) Paleochori Bay, (B) Agia Kyriaki and (C) Spathi Bay (Milos, Greece). See Figure 1 for location.

Figure 8. AUV photomosaics over the drone imagery (background image), and associated interpretation, from of (A) Paleochori East, (B) Paleochori West and (C) Spathi. See Figure 1 for location. 
Figure 9. Comparison plot of seafloor surfaces estimated using drone and AUV over an equal survey area. Squares: Spathi Bay. Circle: Paleochori West. Star: Paleochori East. Pink background: WHPs. Red background: DHPs. Brown background: Posidonia oceanica.

Figure 10. (A) Subseafloor temperature at $35 \mathrm{~cm}$ depth observed for the different seafloor types observed at the hexagon (blue stars) and the rest of Paleochori Bay (red circles). The black crosses correspond to the mean temperatures. (B) Blue stars correspond to the "Hexagon" study area, the red open circles to measurements throughout Paleochori Bay, and the black crosses to the mean gradients for each seafloor type (see temperature and gradient values in Table 5, Table S1, and Table S2). WHPs: White Hydrothermal Patches. WHPs/BT: Transitional area. BT: Bioturbation. NS: Non-hydrothermalized Sand. HS: Hydrothermalized Sand. FL: Fluids.

Figure 11. Location of temperature measurements on the hexagon area, with corresponding temperatures. Location of this site is shown in Figure 1.

Figure 12. (A) Location of temperature measurements over the Paleochori Bay drone photomosaic, with the corresponding temperatures. (B) Zoom on two study sites, indicated by the box in (A).

Figure 13. 3D interpretative sketch of the organization of the subseafloor thermal regime, with association to the seafloor hydrothermal patterns. Temperatures are higher beneath white bacterial mats $(\mathrm{BM})$ and decrease laterally towards sandy seafloor unaffected by hydrothermal activity. Localized high-temperature outflows are also encountered (red triangles). Bioturbated areas (BT, purple areas) are often associated with bacterial mats but are also found away from hydrothermal patterns. Heat flux is partitioned between conductive flow (straight black arrows) and advective flow (red and blue wavy arrows). 
Table 1. Details and specifications on the temperature sensors used to acquire the data presented in this paper.

Table 2. Surfaces for all seafloor types identified on drone photomosaics.

Table 3. Surfaces for all seafloor types identified on AUV photomosaics.

Table 4. Seafloor surfaces estimated from AUV surveys and from aerial drone surveys calculated over the areas surveyed by the AUV.

Table 5. Summary of subseafloor temperatures (at $35 \mathrm{~cm}$ ) and vertical thermal gradients at Paleochori Bay, including the Hexagon study site. Number of observations in parenthesis. WHPs: White Hydrothermal Patches. WHPs/BT: Transitional area. BT: Bioturbation. NS: Nonhydrothermalized Sand. HS: Hydrothermalized Sand. FL: Fluids.*Negative measured values are likely associated with advection and complex thermal regimes, not conductive regimes.

Table 6. Estimates of heat flux in MW for each bay. Estimates are provided for both diffuse and conductive heat flow, based on the surfaces in Table 2 corresponding to WHPS surfaces. For diffuse flow the minimum and maximum values correspond to outflow velocities of 1 and $5 \mathrm{~mm} / \mathrm{s}$. See text for the parameters used in the calculations including thermal conductivity, heat capacity, and density. 


\section{Supplementary figure captions}

Figure S2. Drone photomosaics from our study areas of (A) Paleochori Bay, (B) Agia Kyriaki and (C) Spathi Bay (Milos, Greece).

Figure S2. AUV photomosaics over the drone imagery (background image) from of (A) Paleochori East, (B) Paleochori West and (C) Spathi.

Figure S3. (A) Drone photomosaic, (B) Original AUV photomosaic showing shifts and distortions relative to the background drone photomosaic, (C) New AUV photomosaic shifted and wrapped relative to the drone photomosaic to provide a geographically consistent dataset.

Figure S4. White and dark hexagonal patterns observed at Spathi Bay on drone imagery (A) and AUV imagery $(\mathrm{B}, \mathrm{C})$.

Figure S5. (A) Drone photomosaic showing mobile seagrass at the seafloor (dark lineations). Dead seagrass piles up parallel to ripple marks as deposition is controlled by currents. (B) and (C) Images from divers of areas visible in (A).

Table S1. Master table of temperature data acquired at the Hexagon study site. Values are sorted by profile and then by probe. Absolute coordinates are based on GPS data. Relative coordinates are based on the GIS mapping. Distance along profile is calculated using the Poseidon instrument as the origin (distance $=0$ ). Negative values are for the inside of the hexagon while positive values are for the outside. Time in hours is in UTC, with time $=0$ corresponding to 25/09/2019 at 00:00. Start and end of deployments were handpicked to readjust uncertainties from GPS time that might influence the final temperature values. Unless otherwise specified, temperatures reported correspond to the mean of the last minute of deployment, when the record is most stable. Red 
cells indicate measurements with no depth data available, and the nominal rod length is used instead. Light green cells indicate records where the reported temperature does not correspond to the average of the last minute, as reported and explained in the text. WHPs: White Hydrothermal Patches. WHPs/BT: Transition between WHPs and bioturbated areas (BT). NS: Nonhydrothermalized Sand.

Table S2. Master table of temperature data acquired throughout Paleochori Bay. Values are sorted and reported by dive, probe, and deployment. Absolute coordinates are based on GPS data. Relative coordinates are based on GIS maps after placing measurements on the photomosaics. Time in hours is in UTC, with time $=0$ corresponding to 25/09/2019 at 00:00. Start and end of deployments were handpicked to readjust uncertainties from GPS time that might influence the final temperature values. reported correspond to the mean of the last minute of deployment, when the record is most stable Red cells indicate measurements with no depth data available, and the nominal rod length is used instead. Light green cells indicate records where the reported temperature does not correspond to the average of the last minute, as reported and explained in the text (usually 30 seconds). Light red cells indicate records where the highest temperature is reported instead, and corresponding to short deployments where the temperature record was far from steady state, as indicated in the text. WHPs: White Hydrothermal Patches. WHPs/BT: Transition between WHPs and bioturbated areas (BT). NS: Non-hydrothermalized Sand. HS: Hydrothermalized Sand. FL: Fluids. 


\section{References}

Aliani, S., Amici, L., Dando, P. R. and Meloni, R. (1998a). Time series and bottom temperature in a marine shallow water hydrothermal vent off Milos Island (Aegean Volcanic Arc): preliminary results. Rapp. Comm. ht. Mer, 35, 46-47.

Aliani, S., Bianchi, N., Cocito, S., Dando, P.R., Meloni, R., Morri, C., Adelbert, A., Peirano, A. and Ziebis, W. (1998b). A map of seagrass meadows in Palaeochori Bay (Milos Island, Greece), a marine aera with hydrothermal activity. Rapports et Proces Verbaux- Commission Internationale pour l'Exploration Scientifique de la mer 35, 512-513.

Aliani, S., Meloni, R. and Dando, P.R. (2004). Periodicities in sediment temperature time-series at a marine shallow water hydrothermal vent in Milos Island (Aegean Volcanic arc, Eastern Mediterranean). J. Marine Syst. 46, 109-119. doi:10.1016/j.jmarsys.2003.11.015

Barreyre, T., Escartin, J., Garcia, R., Cannat, M., Mittelstaedt, E. and Prados, R. (2012). Structure, temporal evolution, and heat flux estimates from the Lucky strike deep-sea hydrothermal field derived from seafloor image mosaics. Geochem. Geophys. Geosyst. 13 (4), Q04008. https://doi.org/10.1029/2011GC003990

Barreyre, T., J. Escartín, R. A. Sohn, M. Cannat, V. Ballu, and W. C. Crawford (2014), Temporal variability and tidalmodulation of hydrothermal exit-fluidtemperatures at the Lucky Strike deepsea ventfield, Mid-Atlantic Ridge, J. Geophys. Res. Solid Earth, 119, 2543-2566, doi:10.1002/2013JB010478 
Bayraktarov, E., Price, R. E., Ferdelman, T. G., and Finster, K. (2013). The pH and pCO2 dependence of sulfate reduction in shallow-sea hydrothermal CO2-venting sediments (Milos Island, Greece). Frontiers in Microbiology, 4, 111. doi: 10.3389/fmicb.2013.00111

Bianchi, C. N., Paul R. Dando and Carla Morri (2011). Increased diversity of sessile epibenthos at subtidal hydrothermal vents: seven hypotheses based on observations at Milos Island, Aegean Sea, doi:10.1080/19475721.2011.565804.

Botz, R., Stüben, D., Gisela, W., Bayer, R., Schmitt, M. and Eckhard, F. (1996). Hydrothermal gases offshore Milos Island, Greece. Chem. Geol. 130, 161-173.

Brinkhoff, T., Sievert, S. M., Kuever, J., and Muyzer, G. (1999). Distribution and diversity of sulfur-oxidizing Thiomicrospira spp. at a shallow-water hydrothermal vent in the Aegean Sea (Milos, Greece). Applied and Environmental Microbiology, 65(9), 3843-3849. doi: 10.1128/AEM.65.9.3843-3849.1999

Callac, N., Posth, N. R., Rattray, J. E., Yamoah, K. K., Wiech, A., Ivarsson, M., Hemmingson, C., Kilias, S., Argyraki, A., Broman, C., Skogby, H., Smittenberg, R. and Chi Fru, E. (2017). Modes of carbon fixation in an arsenic and $\mathrm{CO} 2$-rich shallow hydrothermal ecosystem. Scientific Reports, 7(1), 1-14. https://doi.org/10.1038/s41598-017-13910-2

Campos, R., Gracias, N., and Ridao, P. (2016). Underwater Multi-Vehicle Trajectory Alignment and Mapping Using Acoustic and Optical Constraints. Sensors, 16(3), 387. doi: $10.3390 /$ s 16030387 
Carreras, M., Hernandez, J. D., Vidal, E., Palomeras, N., Ribas, D. and Ridao, P. (2018). Sparus II AUV-A Hovering Vehicle for Seabed Inspection. IEEE Journal of Oceanic Engineering, 43(2), 344-355. doi:10.1109/joe.2018.2792278

Dando, P.R., Hughes, J.A., Leahy, Y., Taylor, L.J. and Zivanovic, S. (1995a). Earthquakes increase hydrothermal venting and nutrient inputs into the Aegean. Cont. Shelf Res. 15, 655-662. doi:10.1016/0278-4343(94)E0031-G

Dando, P.R., Hughes, J.A., Leahy, Y., Niven, S.J., Taylor, L.J. and Smith, C. (1995b). Gas venting rates from submarine hydrothermal areas around the island of Milos, Hellenic Volcanic Arc. Cont. Shelf Res. 15, 913-929.

Dando, P.R., Aliani, S., Arabj, H., Bianchi, C.N., Brehmeg, M., Cocito, S., Fowle, S.W., Guodersen, J., Hooper, L.E., Kiilbl, R., Kuever, J., Linke, P., Makropoulos, K.C., Meloni, R., Mique, J.-C., Morri, C., Miiller, S., Robinson, C., Scblesne, H., Sievert, S., Stijhr, R., Stiiben, D., Thomm, M., Varnavas, S.P. and Ziebis, W. (2000). Hydrothermal studies in the Aegean Sea. Phys. Chem. Earth 25, 1-8.

Duran-Toro, V.M., Price, R.E., Maas, M., Brombach, C.C., Pichler, T., Rezwan, K. and Bühring, S.I. (2019). Amorphous arsenic sulfide nanoparticles in a shallow water hydrothermal system. Mar. Chem. 211, 25-36. https://doi.org/10.1016/j.marchem.2019.03.008

Elibol, A., Gracias, N., and Garcia, R. (2010). Augmented state-extended Kalman filter combined framework for topology estimation in large-area underwater mapping. Journal of Field Robotics, 27(5), 656-674. doi:10.1002/rob.20357 
Escartin, J., Barreyre, T., Cannat, M., Garcia, R., Gracias, N., Deschamps, A., Salocchi, A,. Sarradin, P-M. and Ballu, V. (2015). Hydrothermal activity along the slow-spreading Lucky Strike ridge segment (Mid-Atlantic Ridge): Distribution, heatflux, and geological controls. Earth and Planetary Science Letters, 431, 173-185. https://doi.org/10.1016/j.eps1.2015.09.025

Fitzsimons, M.F., Dando, P.R., Hughes, J.A., Thiermann, F., Akoumianaki, I. and Pratt, S.M. (1997). Submarine hydrothermal brine seeps off Milos, Greece: observations and geochemistry. Mar. Chem. 57, 325-340.

Fytikas, M., Innocenti, F., Kolios, N., Manetti, P., Mazzuoli, R., Poli, G., Rita, F. and Villari, L. (1986). Volcanology and petrology of volcanic products from the island of Milos and neighbouring islets. J. Volcanol. Geotherm. Res. 28, 297-317.

Giovannelli, D., d'Errico, G., Manini, E., Yakimov, M., \& Vetriani, C. (2013). Diversity and phylogenetic analyses of bacteria from a shallow-water hydrothermal vent in Milos island (Greece). Frontiers in microbiology, 4, 184. https://doi.org/10.3389/fmicb.2013.00184

Godelitsas, A., Price, R.E., Pichler, T., Amend, J., Gamaletsos, P. and Göttlicher, J. (2015). Amorphous As-sulfide precipitates from the shallow-water hydrothermal vents off Milos Island (Greece). Mar. Chem. 177, 687-696. https://doi.org/10.1016/j. marchem.2015.09.004

Gracias, N., Garcia, R., Campos, R., Hurtos, N., Prados, R., Shihavuddin A.S.M., Nicosevici, T., Elibol, A., Neumann, L. and Escartin, J. (2017). Application Challenges of Underwater Vision. Computer Vision in Vehicle Technology: Land, Sea \& Air. 133-160. 
Houghton, J.L., Gilhooly, W.P., Kafantaris, F.C.A., Druschel, G.K., Lu, G.S., Amend, J.P. and Fike, D.A. (2019). Spatially and temporally variable sulfur cycling in shallow-sea hydrothermal vents, Milos, Greece. Mar. Chem. 208, 83-94. https://doi.org/10. 1016/j.marchem.2018.11.002

Jannasch, H. and Wirsen, C. (1981). Morphological survey of microbial mats near deep-sea thermal vents. Appl Environ Microb 41: 528-538.

Khimasia, A., Rovere, A. and Pichler, T. (2020). Hydrothermal areas, microbial mats and sea grass in Paleochori Bay, Milos, Greece. Journal of Maps, 16(2), 348-356. doi:10.1080/17445647.2020.1748131.

Khimasia, A., Renshaw, C. E., Price, R. E. and Pichler, T. (2021). Hydrothermal flux and porewater geochemistry in Paleochori Bay, Milos, Greece. Chemical Geology, 571, doi: 10.1016/j.chemgeo.2021.120188.

Maki, T., Kondo, H., Ura, T., and Sakamaki, T. (2008). Large-area visual mapping of an underwater vent field using the AUV "Tri-Dog 1". IEEE Journal of Oceanic Engineering, v. Ocean 2008, p. 1135-1702

Marcon, Y., Sahling, H., Borowski, C., dos Santos Ferreira, C., Thal, J. and Bohrmann, G. (2013). Megafaunal distribution and assessment of total methane and sulfide consumption by mussel beds at Menez Gwen hydrothermal vent, based on geo-referenced photomosaics. Deep Sea Research Part I: Oceanographic Research Papers, v. 75, p. 93-109, doi: 10.1016/j.dsr.2013.01.008 
[dataset] Martelat, J.E., Puzenat, V., Escartin, J. and Grandjean, P. (2019). Milos Shallow Water Hydrothermal System: Drone seafloor photomosaics (July/September 2019 fieldwork). SEANOE. https://doi.org/10.17882/77670

Martelat, J. E., Escartín, J. and Barreyre, T. (2020). Terrestrial shallow water hydrothermal outflow characterized from out of space. Marine Geology, 422, 106119. https://doi.org/10.1016/j.margeo.2020.106119

Megalovasilis, P. (2020). Geochemistry of Hydrothermal Particles in Shallow Submarine Hydrothermal Vents on Milos Island, Aegean Sea East Mediterranean. Geochemistry International, 58(2), 151-181. 10.1134/S001670292002007X

Nield, D.A. and Bejan, A. (2006). Convection in Porous Media. Vol. 3. Springer, New York, pp. 640.

Nomikou, P., Papanikolaou, D., Alexandri, M., Sakellariou, D. and Rousakis, G. (2013). Submarine volcanoes along the aegean volcanic arc. Tectonophysics 597-598, 123-146. https://doi.org/10.1016/j.tecto.2012.10.001

Papanikolaou, D., Lekkas, E., Syskakis, D. and Adamopolou, E. (1993). Correlation on neotectonic structures with the geodynamic activity on Milos during the earthquakes of March 1992. Bull. Geol. Soc. Greece 28, 413-428.

Prados, R., Garcia, R., Gracias, N., Escartin, J. and Neumann, L. (2012). A novel blending technique for underwater gigamosaicing. IEEE J. Ocean. Eng. 37. http:// dx.doi.org/10.1109/JOE.2012.2204152 
Price, R.E., Savov, I., Planer-Friedrich, B., Bühring, S.I., Amend, J. and Pichler, T. (2013). Processes influencing extreme As enrichment in shallow-sea hydrothermal fluids of Milos island, Greece. Chem. Geol. 348, 15-26. https://doi.org/10.1016/j.chemgeo.2012.06.007

Price, R.E. and Giovannelli, D. (2017). A review of the geochemistry and microbiology of marine shallow-water hydrothermal vents. Reference Module in Earth Systems and Environmental Sciences. https://doi.org/10.1016/b978-0-12-409548-9.09523-3

[dataset] Puzenat, V., Gracias, N., Martelat, J.E., Escartin, J. and Garcia, R. (2019a). Milos Shallow Water Hydrothermal System: AUV seafloor photomosaics (July 2019 fieldwork). SEANOE. https://doi.org/10.17882/77669

[dataset] Puzenat, V., Escartin, J. and Martelat, J.E. (2019b). Milos Shallow Water Hydrothermal System: Shapefiles for AUV and Drone photomosaic interpretations and instrument locations. SEANOE. https://doi.org/10.17882/77668

[dataset] Puzenat, V., Escartin, J., Barreyre, T. and Martelat, J.E. (2019c). Milos Shallow Water Hydrothermal System: Autonomous temperature records (Summer2019 fieldwork). SEANOE. https://doi.org/10.17882/77656

Ramondenc, P., Germanovich, L. N., Von Damm, K. L., and Lowell, R. P. (2006). The first measurements of hydrothermal heat output at $9^{\circ} 50^{\prime}$ N, East Pacific Rise. Earth Planet. Sci. Lett., 245, 487-497. doi:10.1016/j.eps1.2006.03.023.

Robinson, C., W. Ziebis, S. Muller, K. Eichstaedt, P. Dando, P. Linke, S. Varnavas, P. Megalovasilis, and D. Panagiotaras (1997). In Situ Investigations Of Shallow Water 
Hydrothermal Vent Systems, Palaeochori Bay, Milos, Aegean Sea, The Fourth Underwater Science Symposium: Proceedings, paper number SUT-USS-97-085.

Rudnicki, M.D., and Elderfield, H. (1992). Theory applied to the Mid-Atlantic Ridge hydrothermal plumes: the finite-difference approach. Journal of Volcanology and Geothermal Research, 50, 161-172, doi: 10.1016/0012-821X(92)90136-J.

Salmi, M. S., H. Paul Johnson, M. A. Tivey, and M. Hutnak (2014). Quantitative estimate of heat flow from a mid-ocean ridge axial valley, Raven field, Juan de Fuca Ridge: Observations and inferences. J. Geophys. Res. Solid Earth, 119, 6841-6854. doi:10.1002/ 2014JB011086

Sarrazin, J., Rodier, P., Tivey, M. K., Singh, H., Schultz, A., \& Sarradin, P. M. (2009). A dual sensor device to estimate fluid flow velocity at diffuse hydrothermal vents. Deep Sea Research Part I: Oceanographic Research Papers, 56(11), 2065-2074. doi:10.1016/j.dsr.2009.06.008

Sievert, S. M., Brinkhoff, T., Muyzer, G., Ziebis, W., and Kuever, J. (1999). Spatial heterogeneity of bacterial populations along an environmental gradient at a shallow submarine hydrothermal vent near Milos Island (Greece). Applied and environmental microbiology, 65(9), 3834-3842. doi: 10.1128/AEM.65.9.3834-3842.1999

Tarasov, V.G., Gebruk, A.V., Mironov, A.N., and Moskalev, L.I. (2005). Deep-sea and shallowwater hydrothermal vent communities: Two different phenomena? Chemical Geology, v. 224, no. 1-3, p. 5-39, doi: 10.1016/j.chemgeo.2005.07.021 
Thurnherr, A. M., \& Richards, K. J. (2001). Hydrography and high-temperature heat flux of the Rainbow hydrothermal site (36 14' N, Mid-Atlantic Ridge). Journal of Geophysical Research: Oceans, 106(C5), 9411-9426. https://doi.org/10.1029/2000JC900164.

Valsami-Jones, E., Baltatzis, E., Bailey, E.H., Boyce, A.J., Alexander, J.L., Magganas, A. and Ragnarsdottir, K.V. (2005). The geochemistry of fluids from an active shallow submarine hydrothermal system: Milos island, Hellenic Volcanic Arc. J. Volcanol. Geotherm. Res. 148, 130-151. https://doi.org/10.1016/j.jvolgeores.2005.03.018

Veirs, S. R., McDuff, R. E., and Stahr, F. R. (2006). Magnitude and variance of near-bottom horizontal heat flux at the Main Endeavour hydrothermal vent field. Geochem. Geophys. Geosyst., 7, Q02004. doi:10.1029/2005GC000952

Wenzhöfer, F., Holby, O., Glud, R. N., Nielsen, H. K., and Gundersen, J. K. (2000). In situ microsensor studies of a shallow water hydrothermal vent at Milos, Greece. Marine Chemistry, 69(1-2), 43-54. https://doi.org/10.1016/S0304-4203(99)00091-2

Yücel, M., Sievert, S.M., Vetriani, C., Foustoukos, D.I., Giovannelli, D. and Le Bris, N. (2013). Eco-geochemical dynamics of a shallow-water hydrothermal vent system at Milos Island, Aegean Sea (Eastern Mediterranean). Chem. Geol. 356, 11-20. http://dx.doi.org/10.1016/j.chemgeo.2013.07.020

Ziebis, W., Forster, S., Huettel, M., and Jørgensen, B. B. (1996). Complex burrows of the mud shrimp Callianassa truncata and their geochemical impact in the sea bed. Nature, 382(6592), 619622. 


\section{Declaration of interests}

$\bigotimes$ The authors declare that they have no known competing financial interests or personal relationships that could have appeared to influence the work reported in this paper.

$\square$ The authors declare the following financial interests/personal relationships which may be considered as potential competing interests: 


\section{HIGHLIGHTS}

- Comprehensive study on the shallow-water hydrothermal system of Milos

- Seafloor mapping using drone and AUV imagery

- Correlation between seafloor hydrothermal patterns and subseafloor temperatures

- First estimates of hydrothermal heat fluxes at Milos

- Ecosystems are spatially associated with hydrothermal activity 


\begin{tabular}{lccccc}
\hline \multicolumn{1}{c}{ Sensor } & $\begin{array}{c}\text { Temperature } \\
\text { range }\end{array}$ & Accuracy & Precision & $\begin{array}{c}\text { Rod } \\
\text { length }\end{array}$ & $\begin{array}{c}\text { Sampling } \\
\text { rate }\end{array}$ \\
\hline $\begin{array}{l}\text { WHOI-MISO high- } \\
\text { temperature }\end{array}$ & $0-450^{\circ} \mathrm{C}$ & $\pm 1{ }^{\circ} \mathrm{C}$ & $0.2^{\circ} \mathrm{C}$ & $76.2 \mathrm{~cm}$ & $2 \mathrm{~s}$ \\
WHOI-MISO low- & $0-125^{\circ} \mathrm{C}$ & $\pm 0.22^{\circ} \mathrm{C}$ & $\begin{array}{c}0.025^{\circ} \mathrm{C} \text { at } \\
25^{\circ} \mathrm{C}\end{array}$ & $12.7 \mathrm{~cm}$ & $1 \mathrm{~s}$ \\
temperature & & & $0.1^{\circ} \mathrm{C}$ & $40 \mathrm{~cm}$ & $1 \mathrm{~s}$ \\
NKE S2T6000DH-Ti & $0-450^{\circ} \mathrm{C}$ & $\begin{array}{c} \pm .5^{\circ} \mathrm{C} \text { below } \\
100^{\circ} \mathrm{C} \\
\pm 1.5^{\circ} \mathrm{C}\end{array}$ & $\begin{array}{c}0.310^{\circ} \mathrm{C} \text { at } \\
85^{\circ} \mathrm{C}\end{array}$ & $60 \mathrm{~cm}$ & $1 \mathrm{~s}$ \\
NKE S2T6000D & $0-100^{\circ} \mathrm{C}$ & & & \\
\hline
\end{tabular}


Agia Kyriaki Paleochori Bay Spathi Bay

\begin{tabular}{lccc}
\hline Mapped area & $374754.87 \mathrm{~m} 2$ & $816488.14 \mathrm{~m} 2$ & $295431.67 \mathrm{~m} 2$ \\
\hline White Hydrothermal Patches (WHPs) - Total & $8.18 \%$ & $4.78 \%$ & $1.82 \%$ \\
\hline WHPs - High density & $0.79 \%$ & & \\
WHPs - Medium density & $6.47 \%$ & $1.77 \%$ & $1.29 \%$ \\
WHPs - Low density & $0.92 \%$ & $3.01 \%$ & $0.53 \%$ \\
\hline Dark Hydrothermal Patches & & & $0.64 \%$ \\
\hline Posidonia oceanica & $0.95 \%$ & $2.70 \%$ & $12.22 \%$ \\
\hline
\end{tabular}




\begin{tabular}{lccc}
\hline & Paleochori West & Paleochori East & Spathi \\
\hline Mapped area & $15751.72 \mathrm{~m} 2$ & $24508.72 \mathrm{~m} 2$ & $27401.58 \mathrm{~m} 2$ \\
\hline White Hydrothermal Patches (WHPs) - Total & $34.12 \%$ & $42.84 \%$ & $3.96 \%$ \\
\hline WHPs - High density & $0.50 \%$ & $0.66 \%$ & $0.60 \%$ \\
WHPs - Medium density & $5.63 \%$ & $21.68 \%$ & $3.36 \%$ \\
WHPs - Low density & $27.99 \%$ & $20.50 \%$ & \\
\hline Dark Hydrothermal Patches & & & $1.69 \%$ \\
\hline Bioturbation & $32.04 \%$ & $35.51 \%$ & $7.22 \%$ \\
\hline Cymodocea nodosa & $11.50 \%$ & $2.33 \%$ \\
\hline Posidonia oceanica & & \\
\hline
\end{tabular}




\begin{tabular}{lcc}
\hline & Drone & AUV \\
\hline Spathi - DHPs & $456.11 \mathrm{~m} 2$ & $463.12 \mathrm{~m} 2$ \\
Spathi - Posidonia & $8141.52 \mathrm{~m} 2$ & $7109.29 \mathrm{~m} 2$ \\
Spathi - WHPs & $1152.30 \mathrm{~m} 2$ & $1086.15 \mathrm{~m} 2$ \\
Paleochori East - WHPs & $9533.90 \mathrm{~m} 2$ & $10501.99 \mathrm{~m} 2$ \\
Paleochori West - WHPs & $5229.23 \mathrm{~m} 2$ & $5374.22 \mathrm{~m} 2$ \\
\hline
\end{tabular}




\begin{tabular}{|c|c|c|c|c|c|c|}
\hline $\begin{array}{c}\text { Temperature } \\
\left({ }^{\circ} \mathrm{C}\right)\end{array}$ & & & & & & \\
\hline & $\begin{array}{c}\text { WHPs }(\mathrm{n}= \\
12)\end{array}$ & $\begin{array}{c}\text { WHPs/BT (n } \\
=7)\end{array}$ & $\begin{array}{c}\text { BT (n }= \\
21)\end{array}$ & $\begin{array}{c}\text { NS (n }= \\
11)\end{array}$ & $\begin{array}{c}\text { HS (n }= \\
19)\end{array}$ & FL $(n=9)$ \\
\hline Min & 52.83 & 35.39 & 21.74 & 21.82 & 30.98 & 35.01 \\
\hline Max & 73.01 & 60.75 & 41.42 & 32.54 & 95.47 & 156.74 \\
\hline Mean & $\begin{array}{c}66.81 \pm \\
5.25\end{array}$ & $47.93 \pm 8.26$ & $\begin{array}{c}28.75 \pm \\
5.65\end{array}$ & $\begin{array}{c}25.83 \pm \\
4.10\end{array}$ & $\begin{array}{c}60.26 \pm \\
16.39\end{array}$ & $\begin{array}{c}96.10 \pm \\
33.60\end{array}$ \\
\hline \multicolumn{7}{|l|}{$\begin{array}{c}\text { Gradient } \\
\left({ }^{\circ} \mathrm{C} / \mathrm{m}\right)\end{array}$} \\
\hline & $\begin{array}{c}\text { WHPs }(n= \\
\text { 5) }\end{array}$ & $\begin{array}{c}\text { WHPs/BT (n } \\
=2)\end{array}$ & $\begin{array}{c}\text { BT (n }= \\
\text { 9) }\end{array}$ & $\begin{array}{c}\text { NS (n }= \\
\text { 3) }\end{array}$ & $\begin{array}{c}\text { HS (n }= \\
19)\end{array}$ & FL $(n=9)$ \\
\hline Min & 26.02 & 56.94 & $-1.30 *$ & 7.90 & 1.06 & 13.00 \\
\hline Max & 94.00 & 59.00 & 50.85 & 24.20 & 133.75 & 415.00 \\
\hline Mean & $\begin{array}{c}63.58 \pm \\
28.30\end{array}$ & $57.97 \pm 1.46$ & $\begin{array}{c}16.50 \pm \\
18.70\end{array}$ & $\begin{array}{c}13.90 \pm \\
8.96\end{array}$ & $\begin{array}{c}51.07 \pm \\
43.75\end{array}$ & $\begin{array}{c}156.67 \pm \\
127.85\end{array}$ \\
\hline
\end{tabular}




\begin{tabular}{ccccc}
\hline Heatflow (MW) & WHPs type Diffuse & \multicolumn{2}{c}{ Conductive } \\
& & Min & Max & \\
\hline Paleochori Bay & MD & 871 & 4355 & 1.6 \\
& LD & 1481 & 7406 & 2.7 \\
& All & 2352 & 11761 & 4.3 \\
\hline Agia Kyriaki & HD & 178 & 892 & 0.3 \\
& MD & 1461 & 7307 & 2.6 \\
& LD & 208 & 1039 & 0.4 \\
& All & 1848 & 9238 & 3.3 \\
\hline Spathi Bay & MD & 230 & 1148 & 0.4 \\
& LD & 94 & 472 & 0.2 \\
& All & 324 & 1620 & 0.6 \\
\hline All Sites & All & 4524 & 22619 & 8.2 \\
\hline
\end{tabular}

Table 


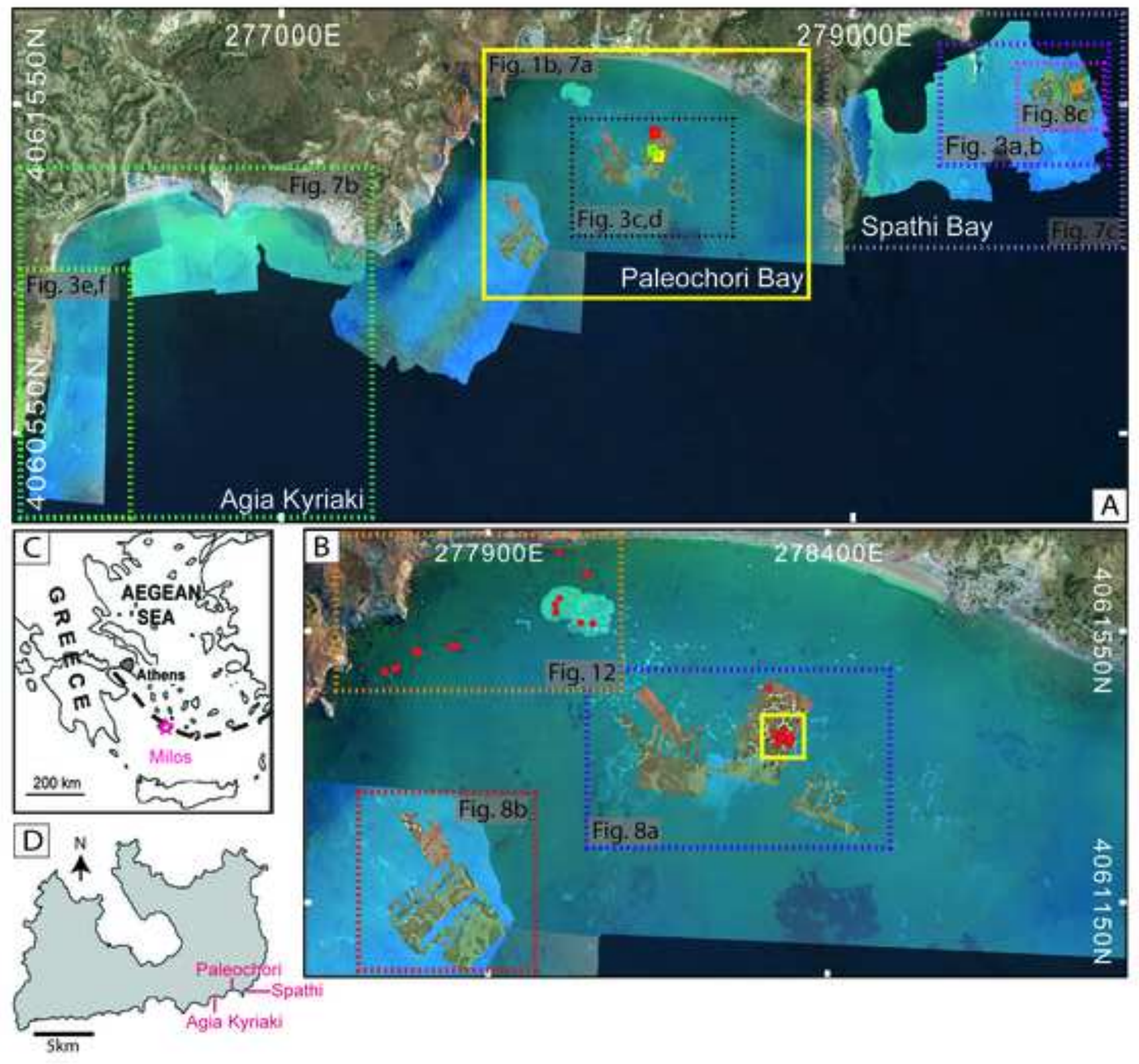




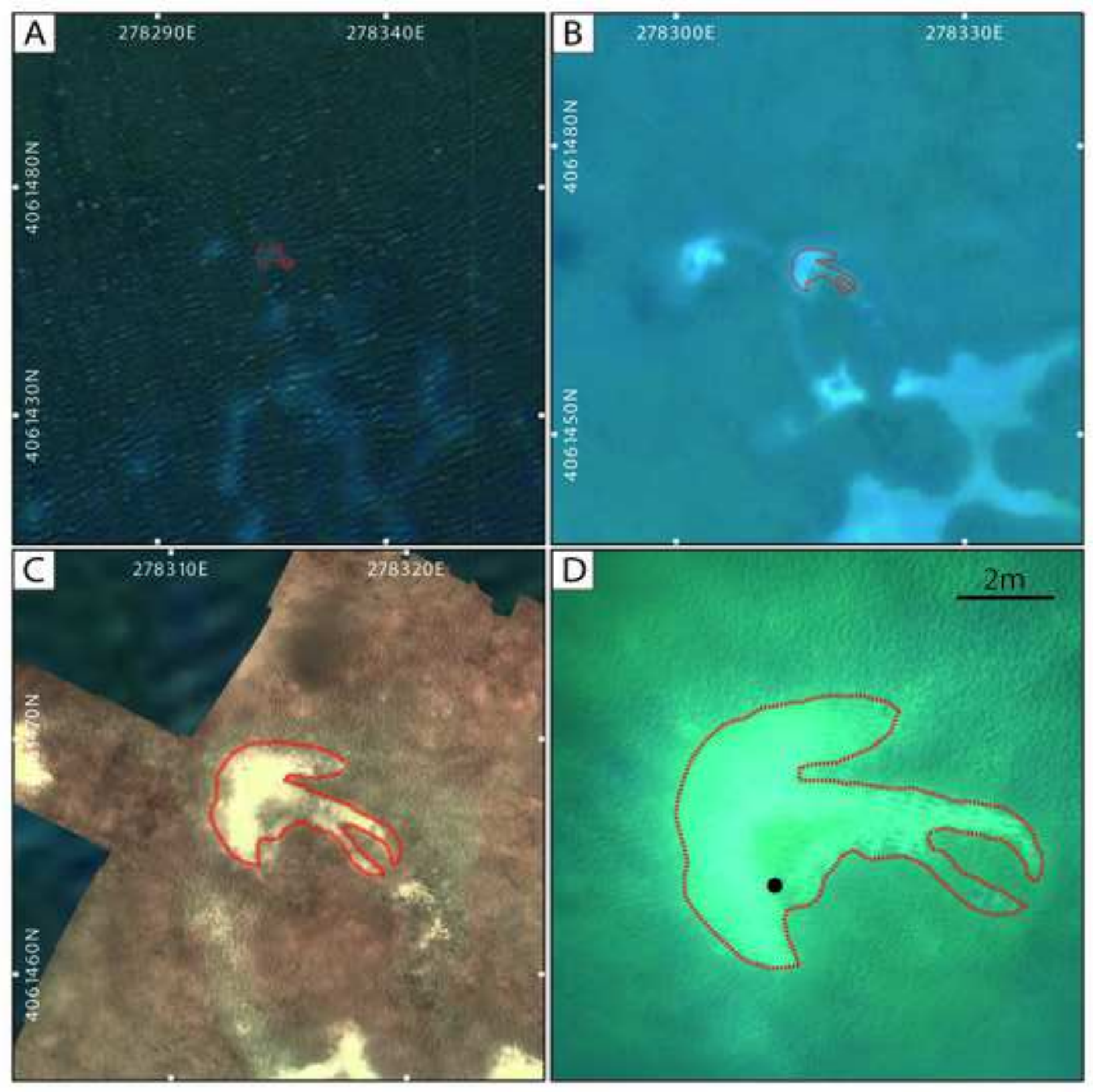




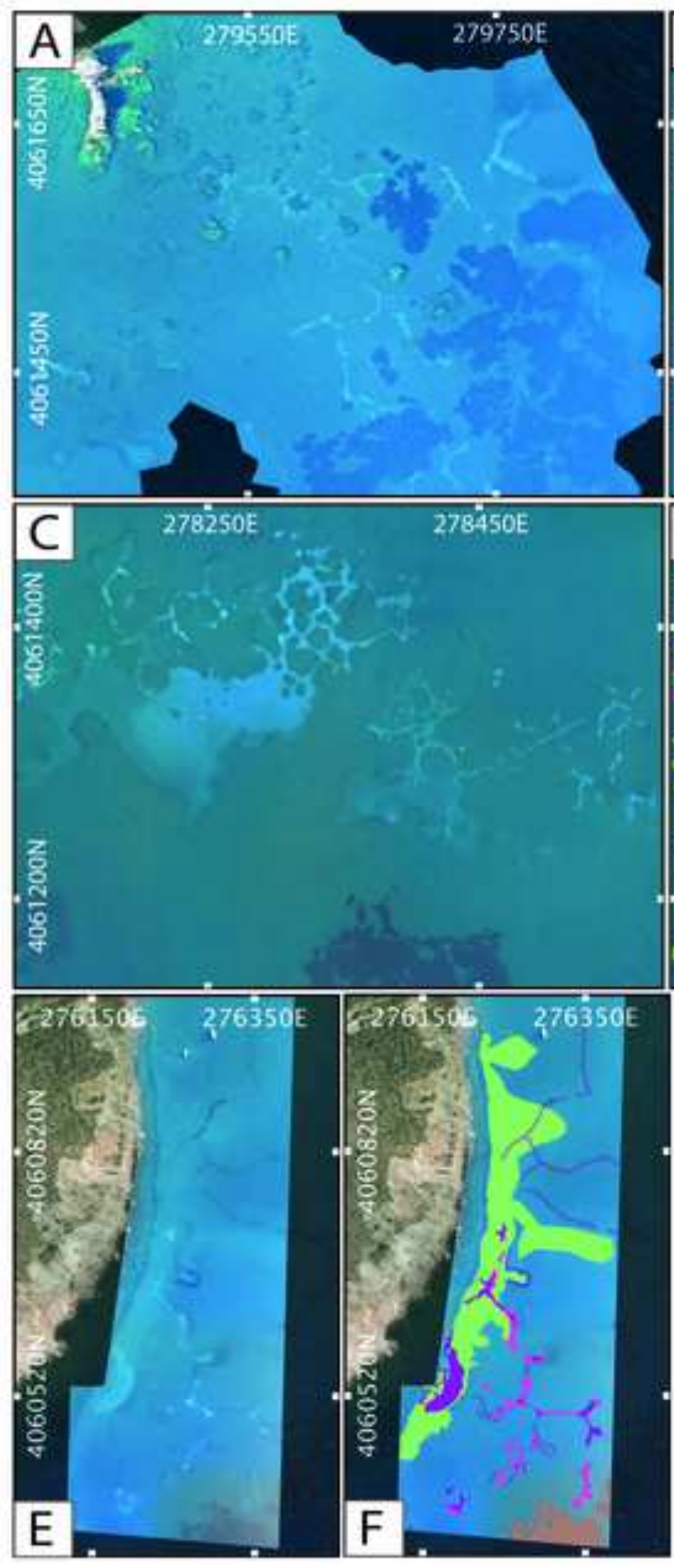

White Hydrothermal Patches

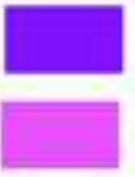

High density

Medium density

Low density

-

Dark Hydrothermal Patches

Dark Lines

Posidonia oceanica 


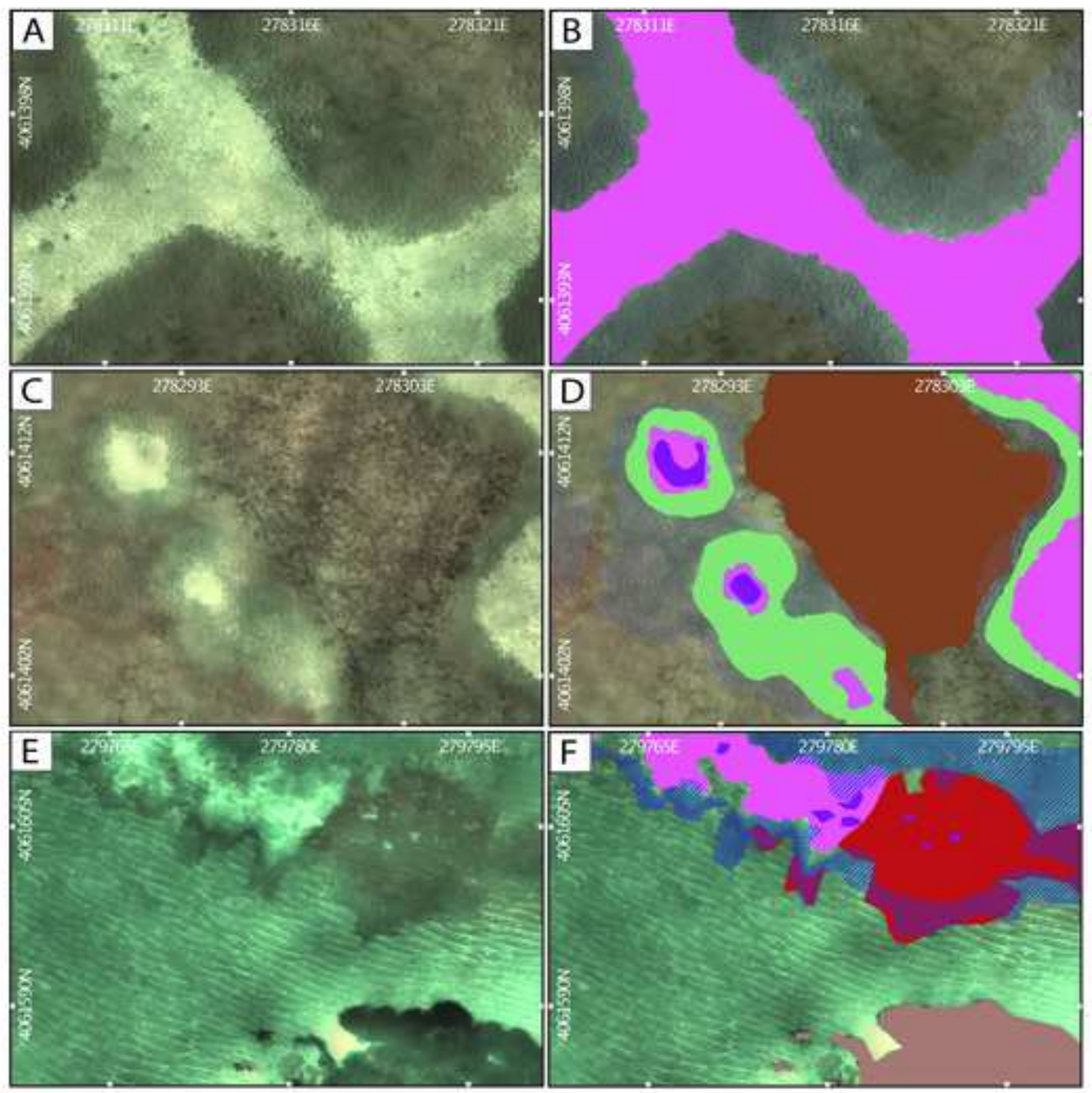

Dark Hydrothermal Patches

Dark Lines

Bioturbation

Cymodocea nodosa
White Hydrothermal Patches

High density

Medium density

Low density

Posidonia oceanica 

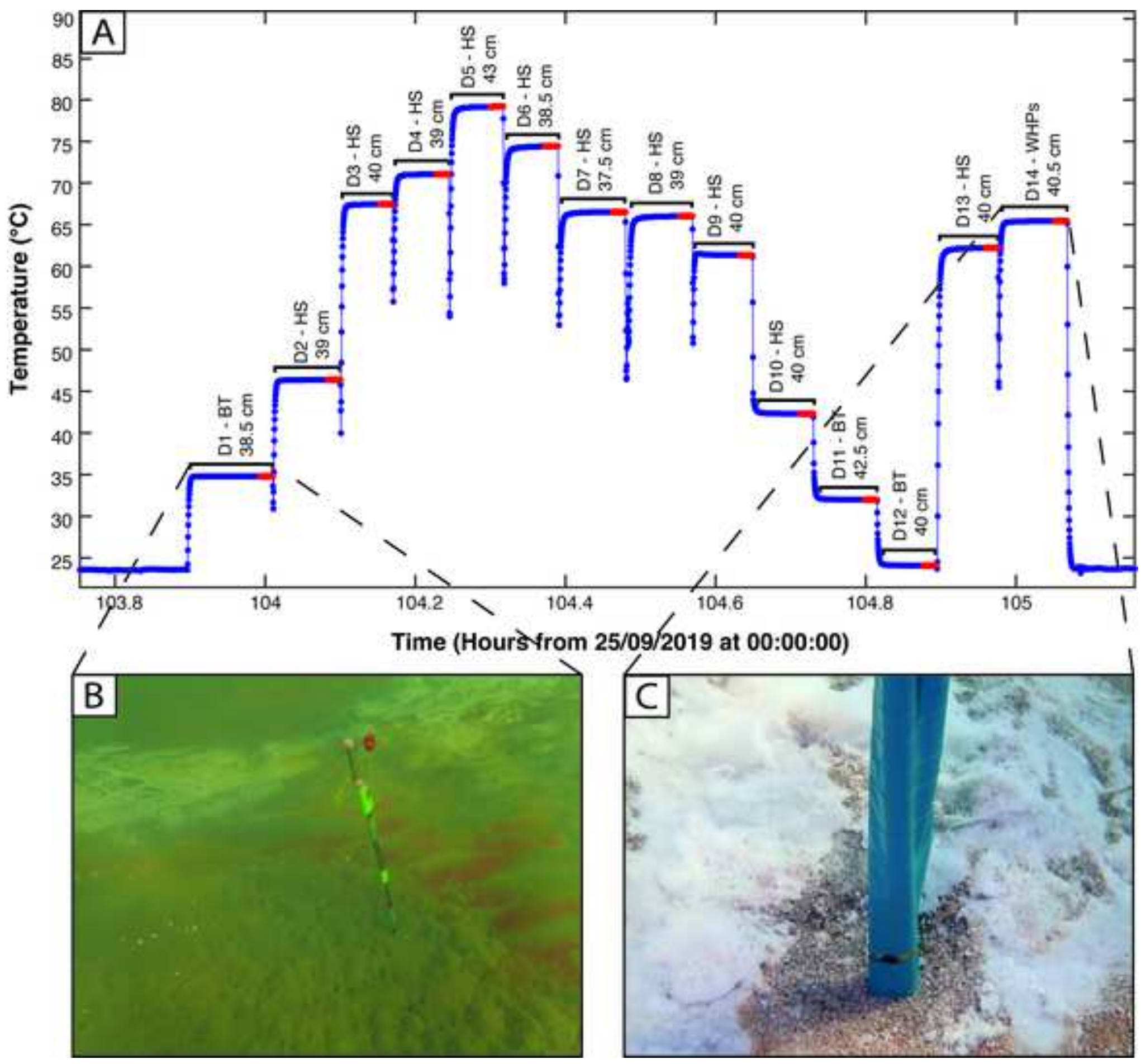

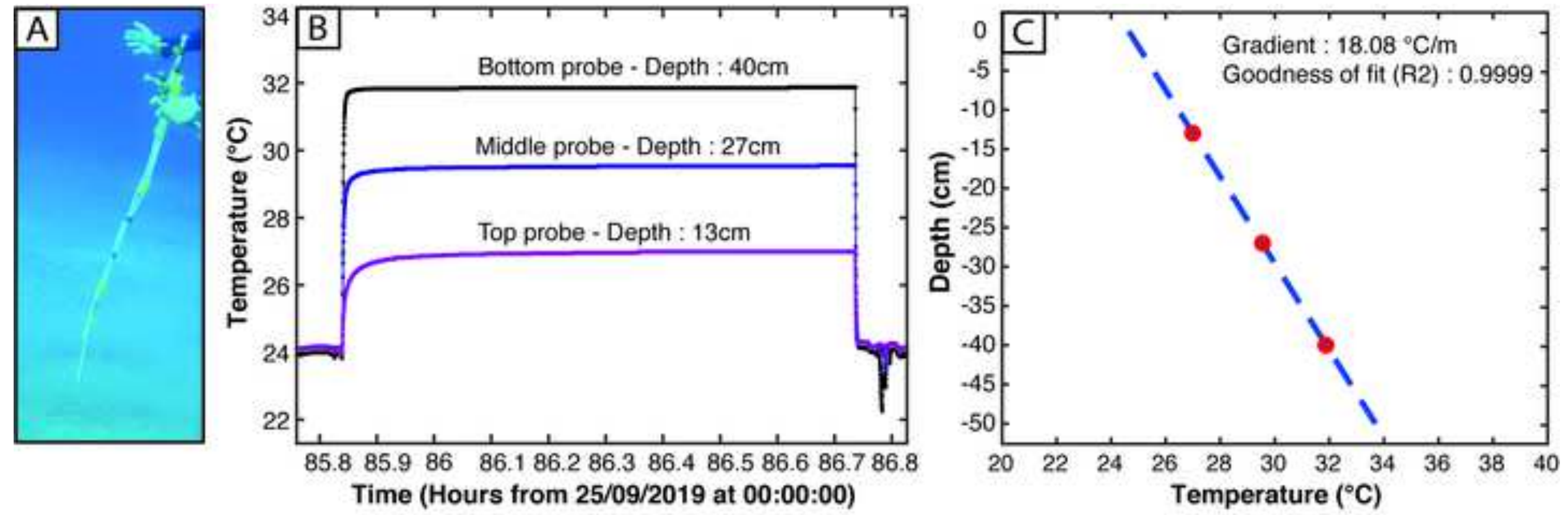


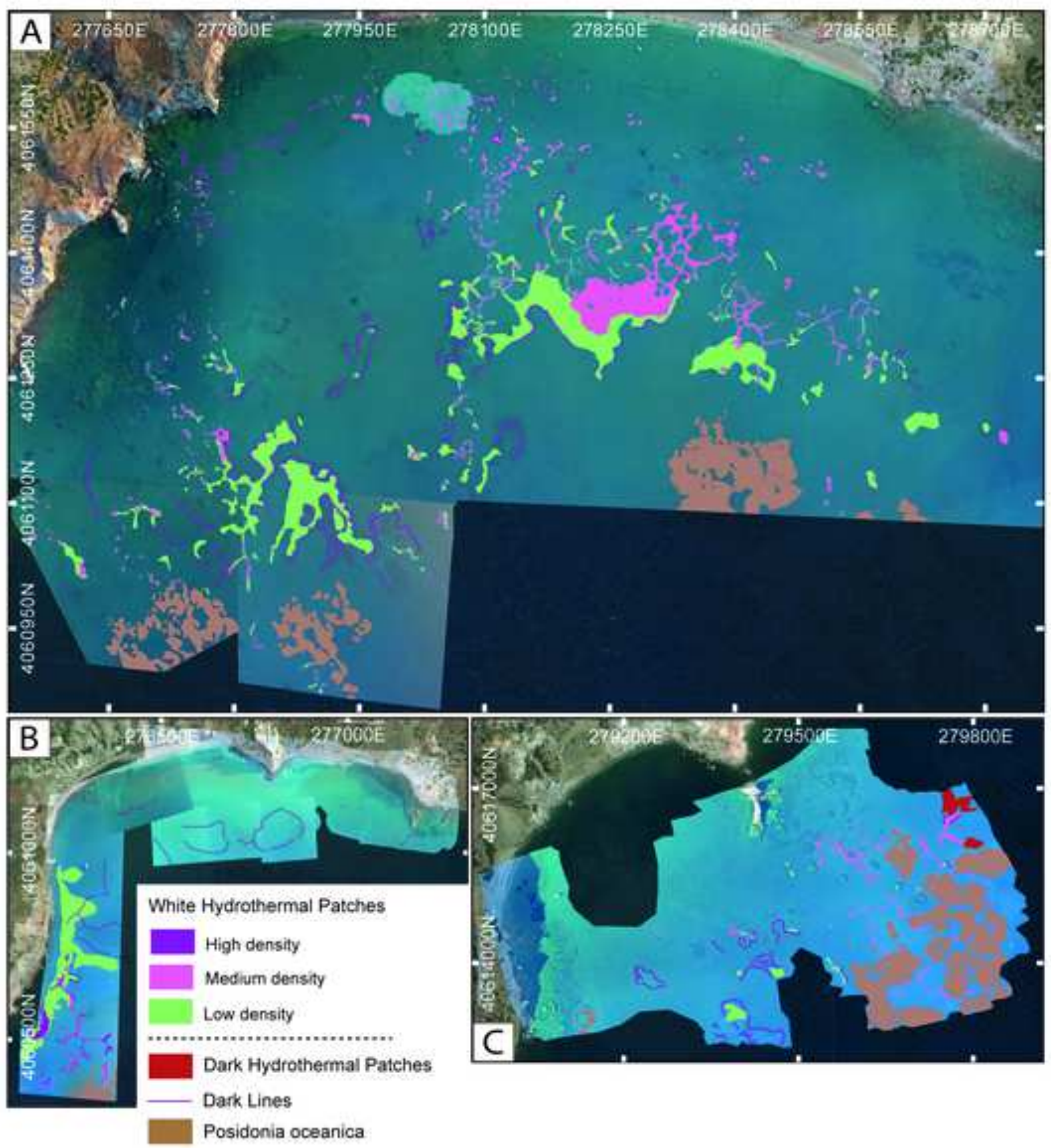




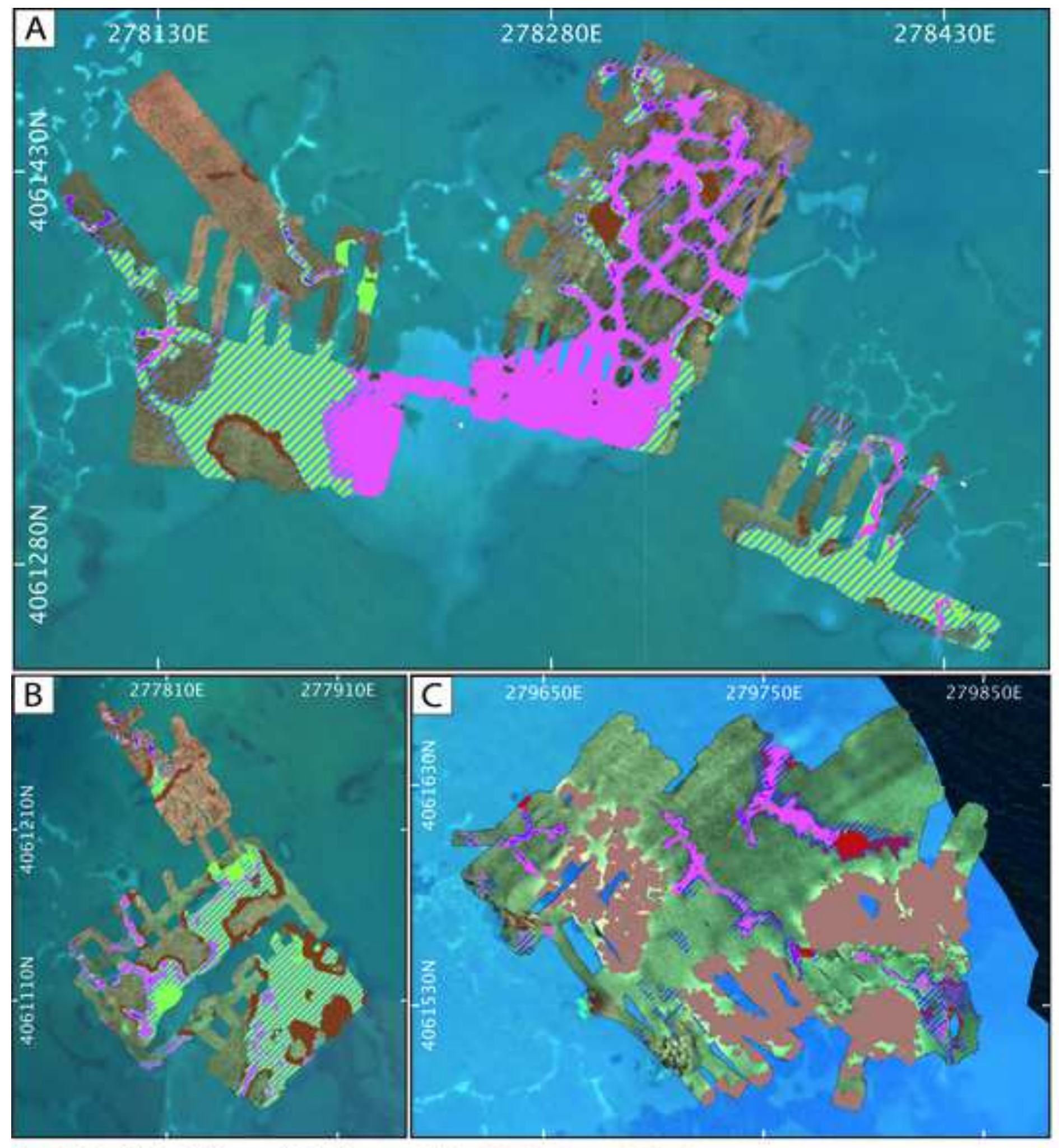

\section{Dark Hydrothermal Patches White Hydrothermal Patches}

Dark Lines

Bioturbation

Cymodocea nodosa
High density

Medium density

Low density 


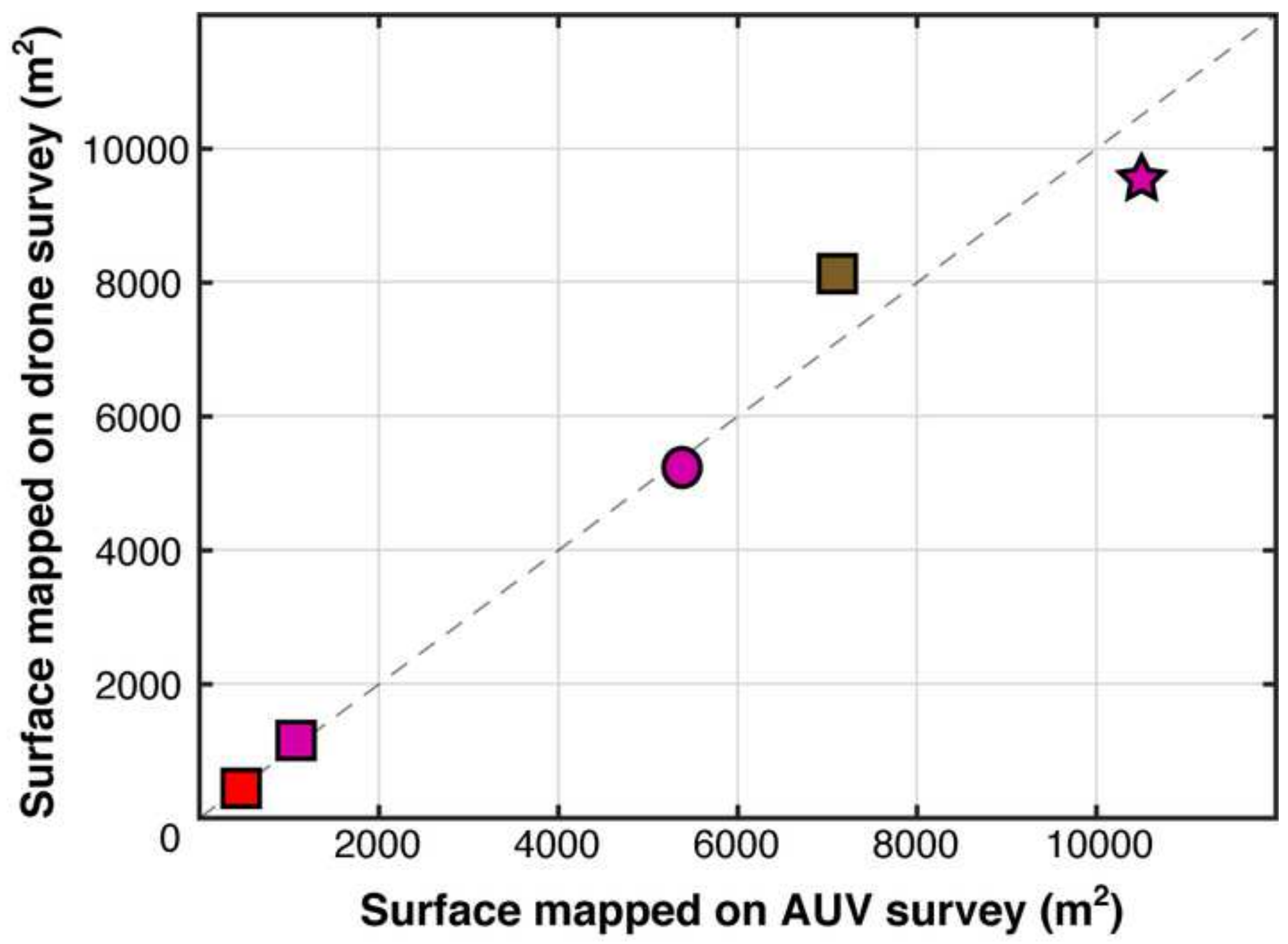



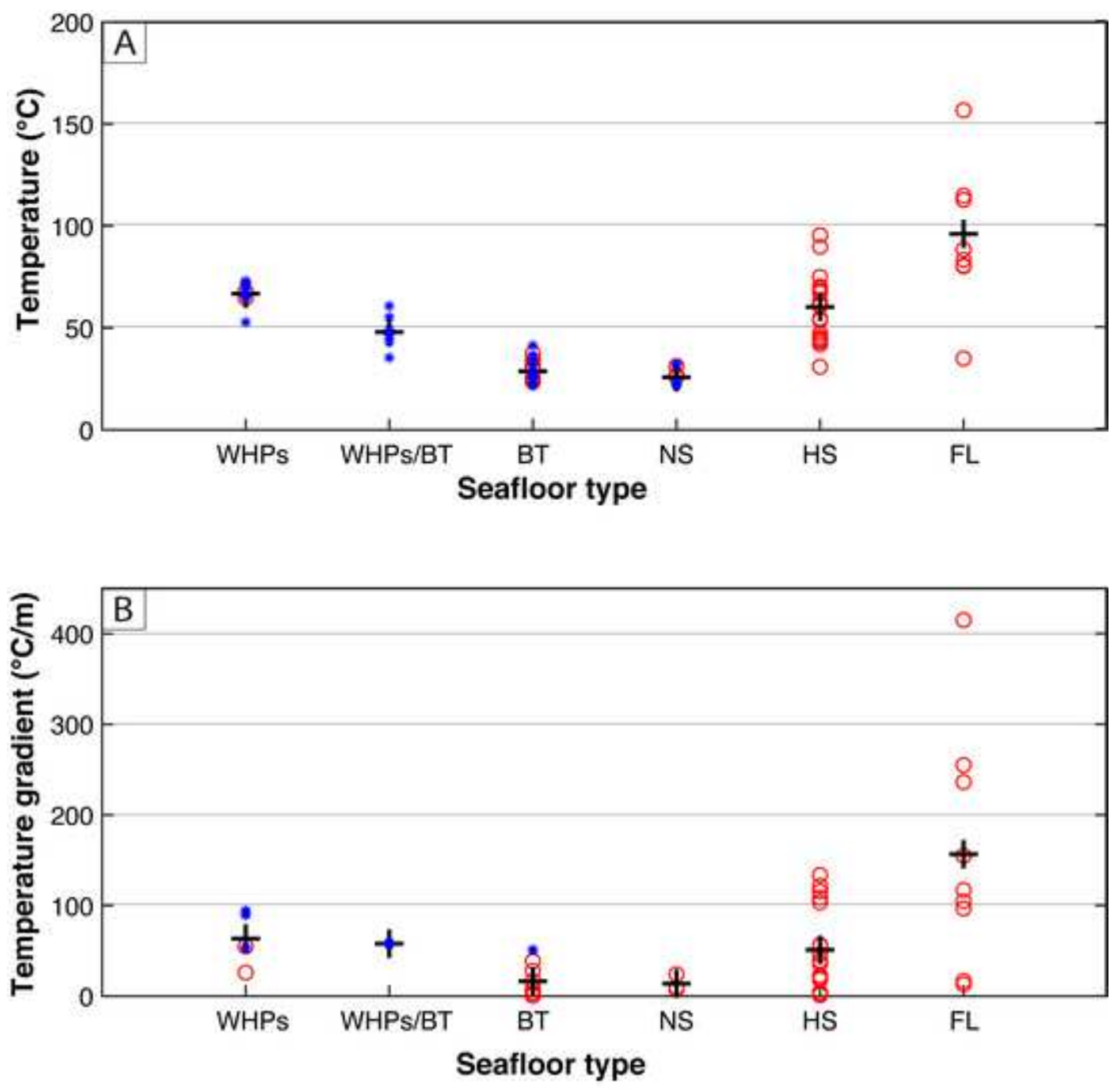


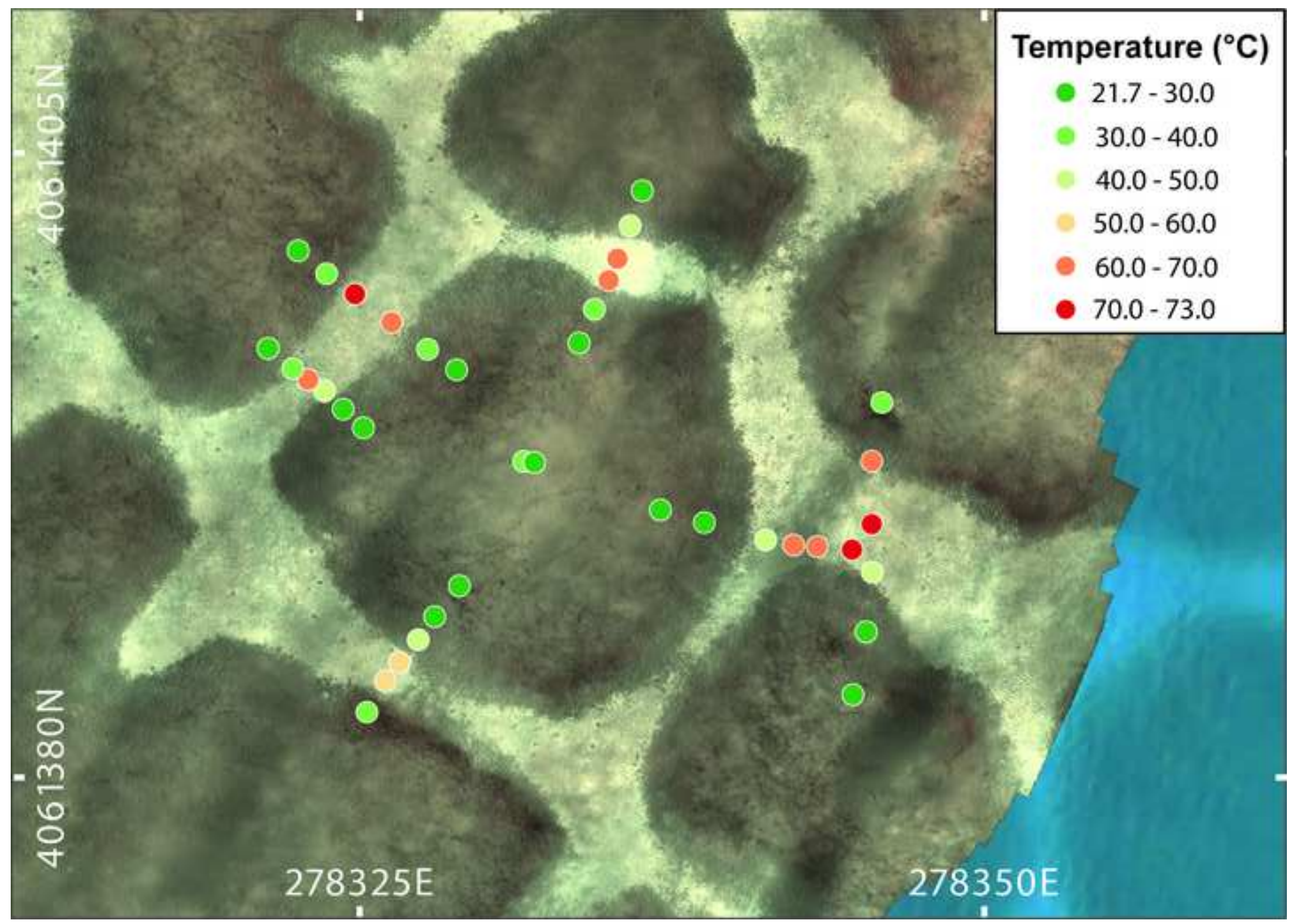



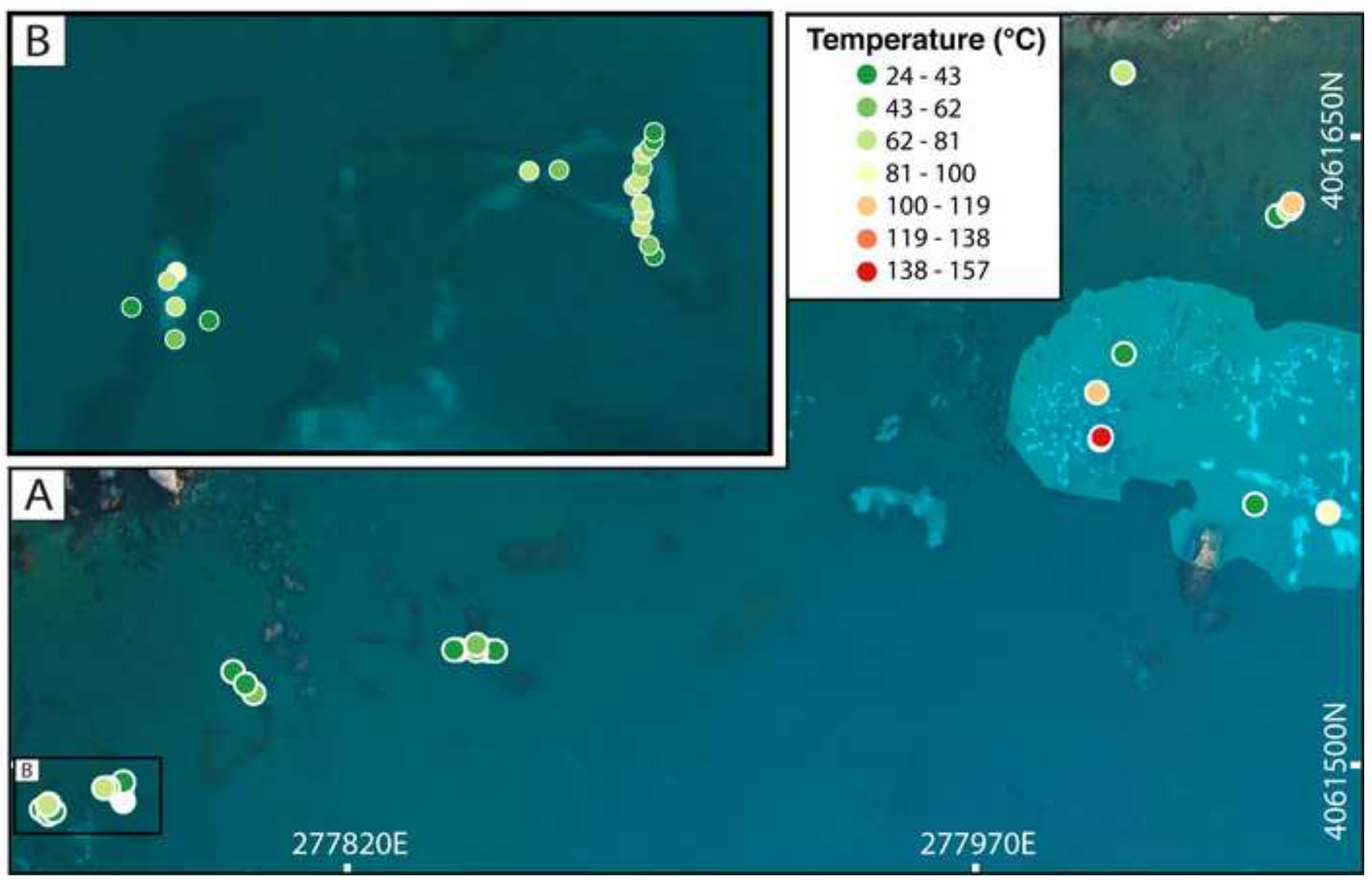


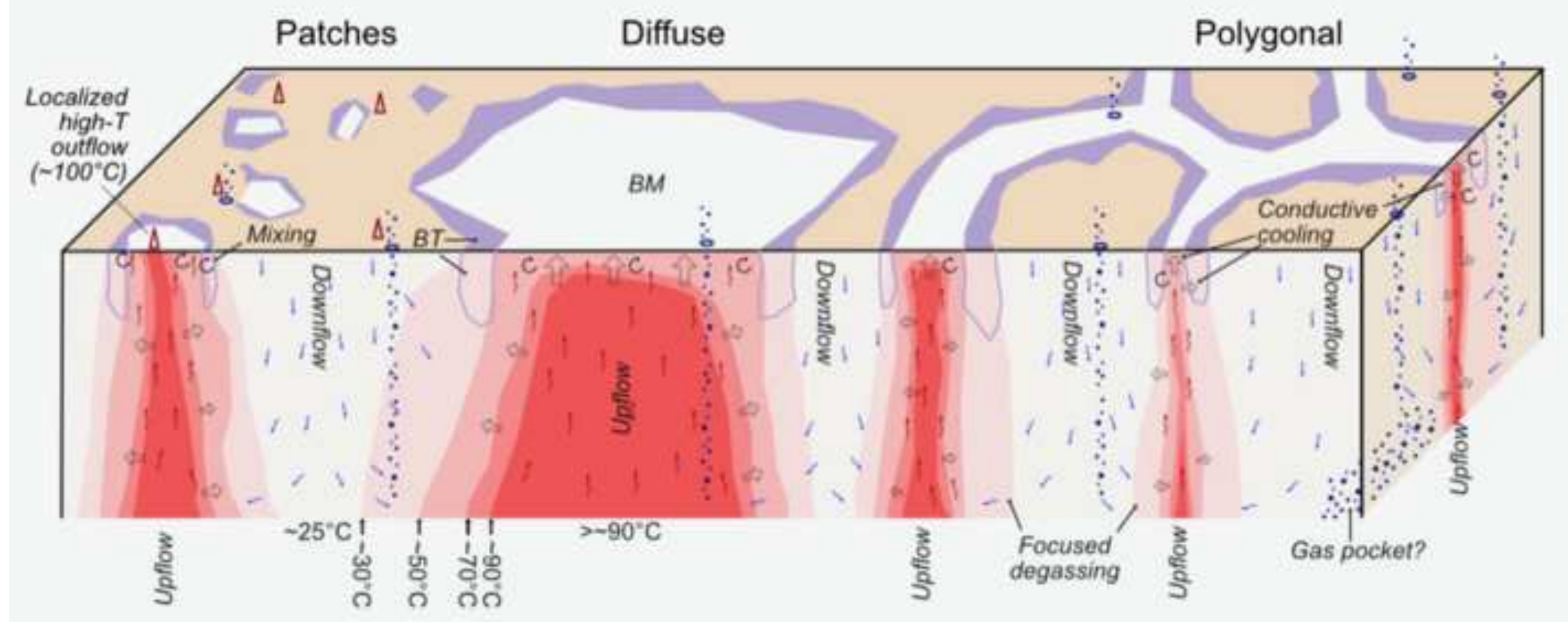




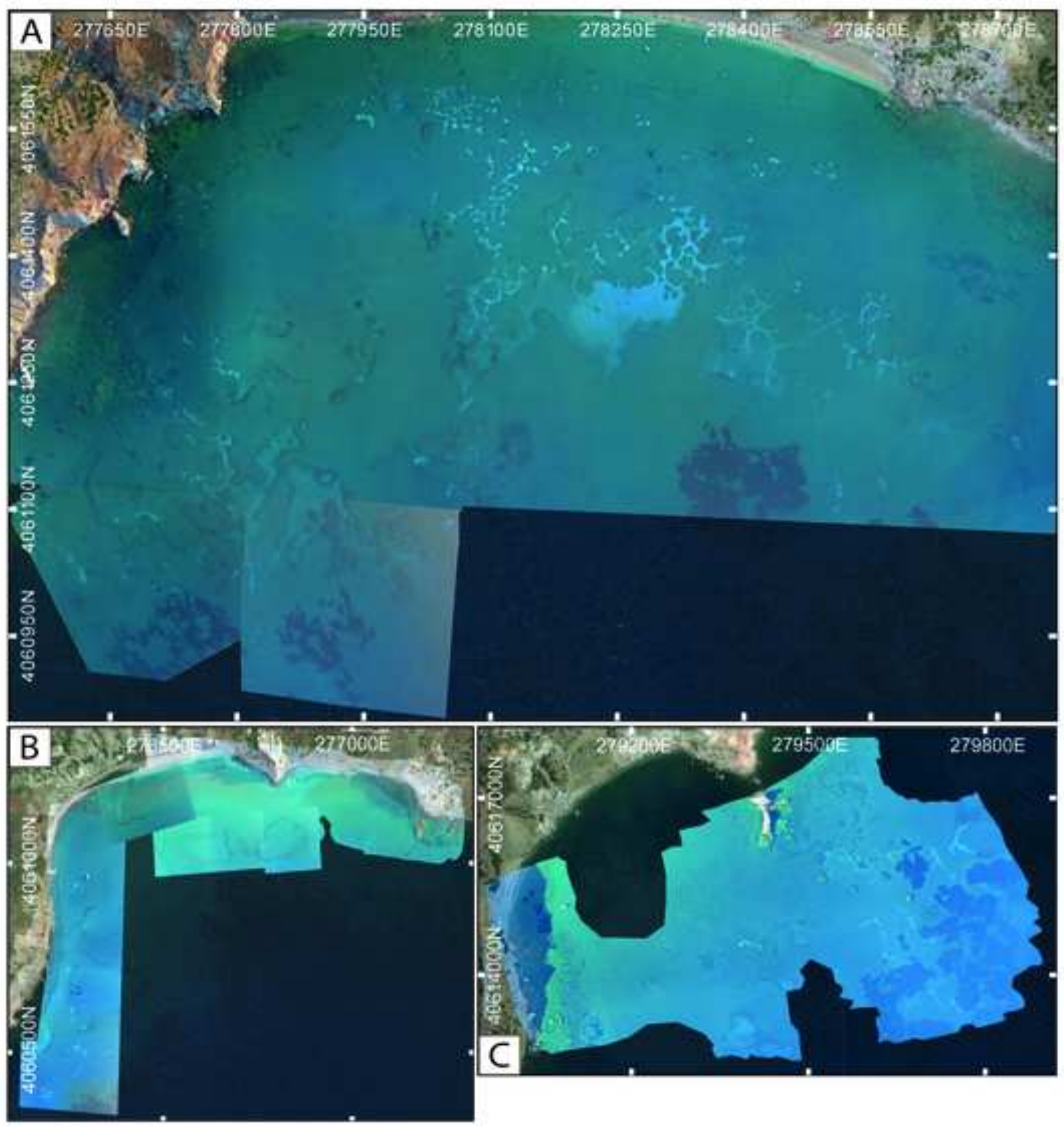




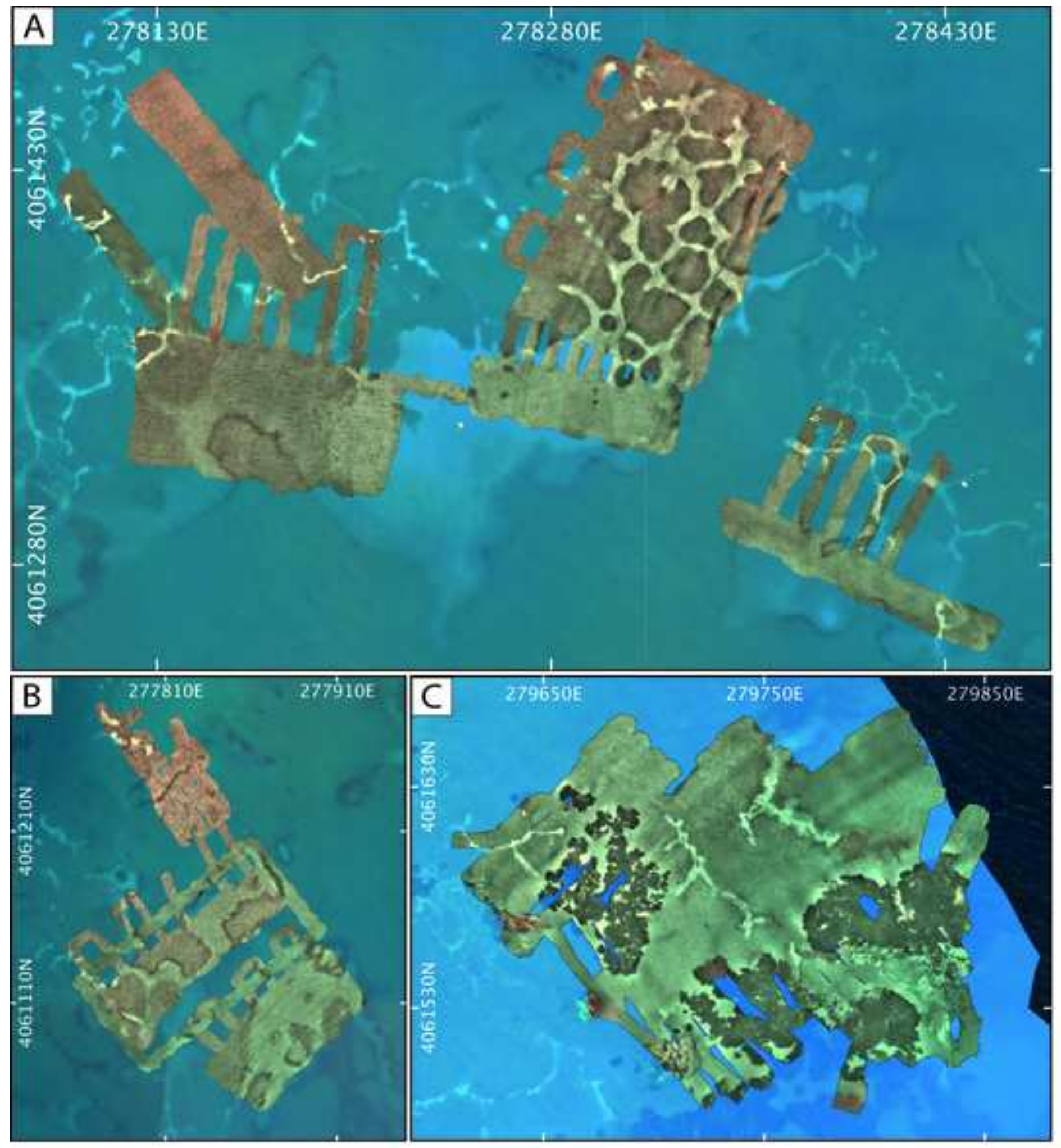




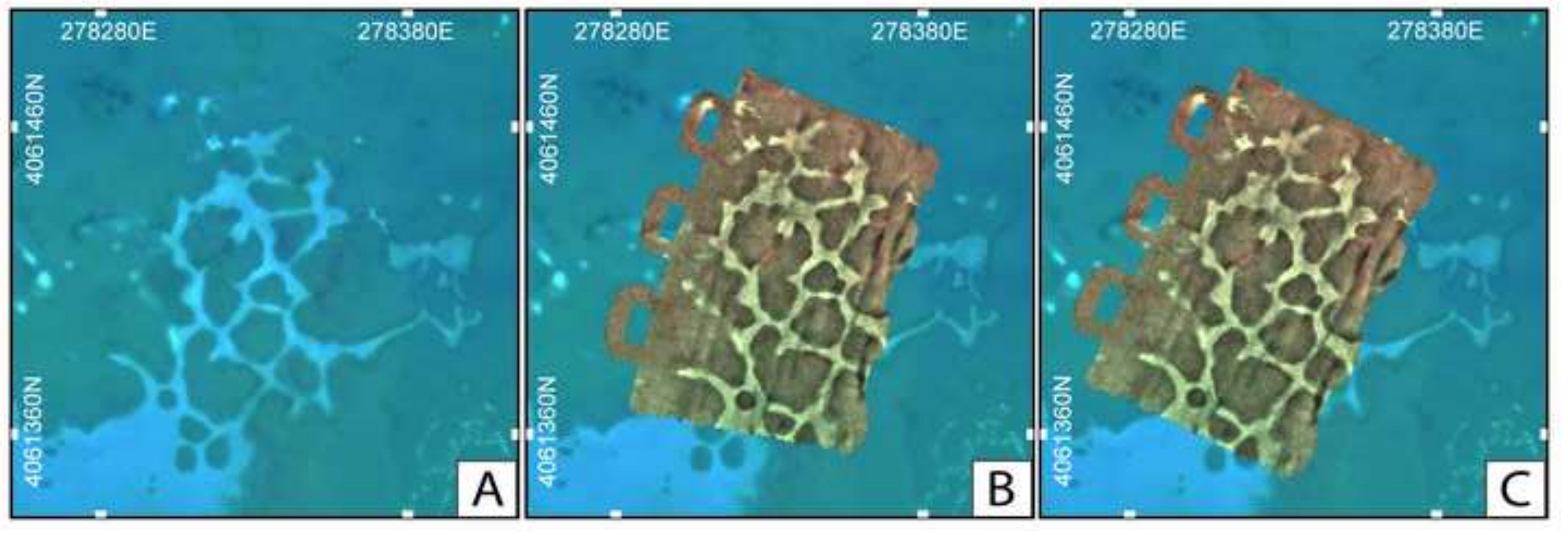




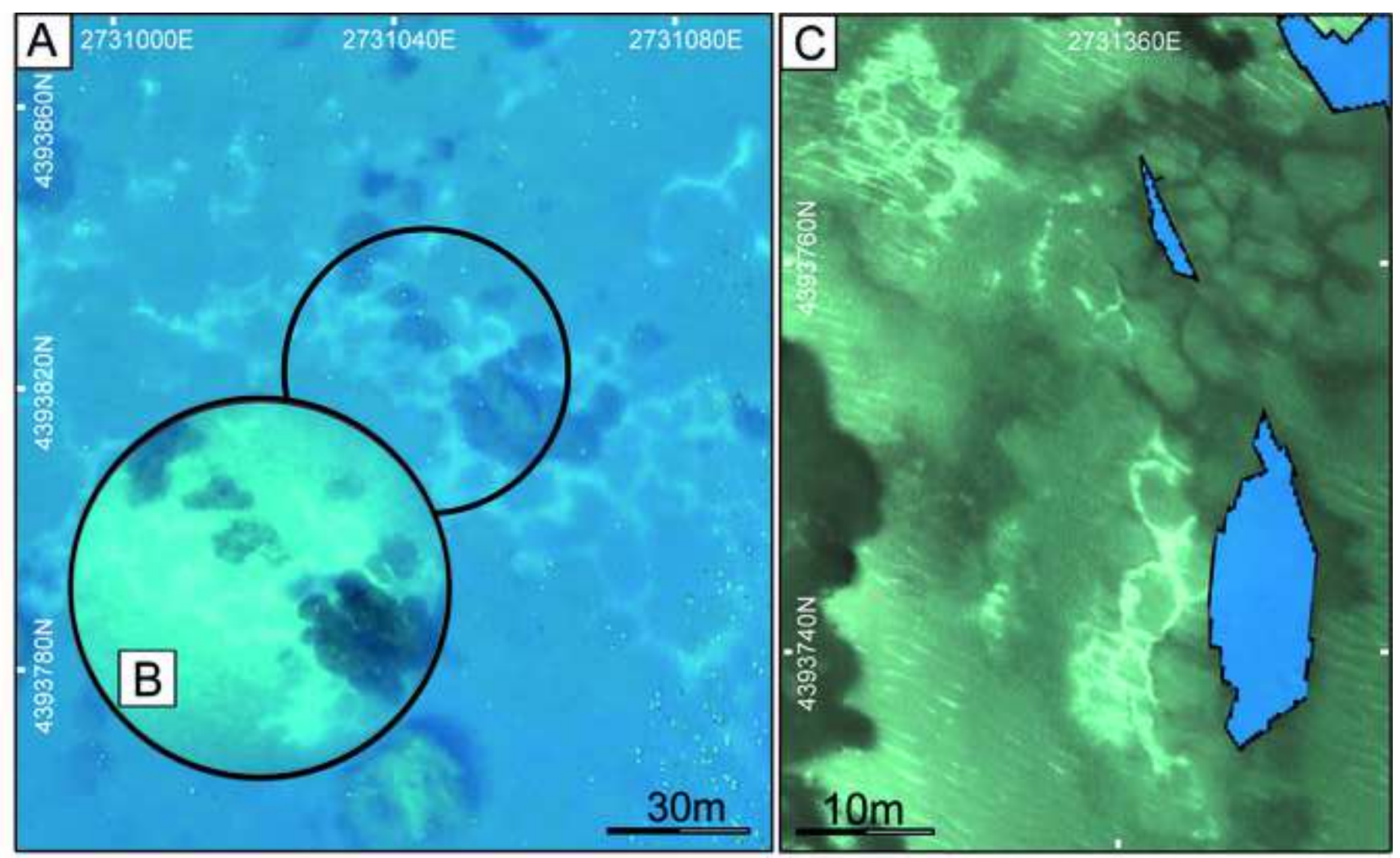




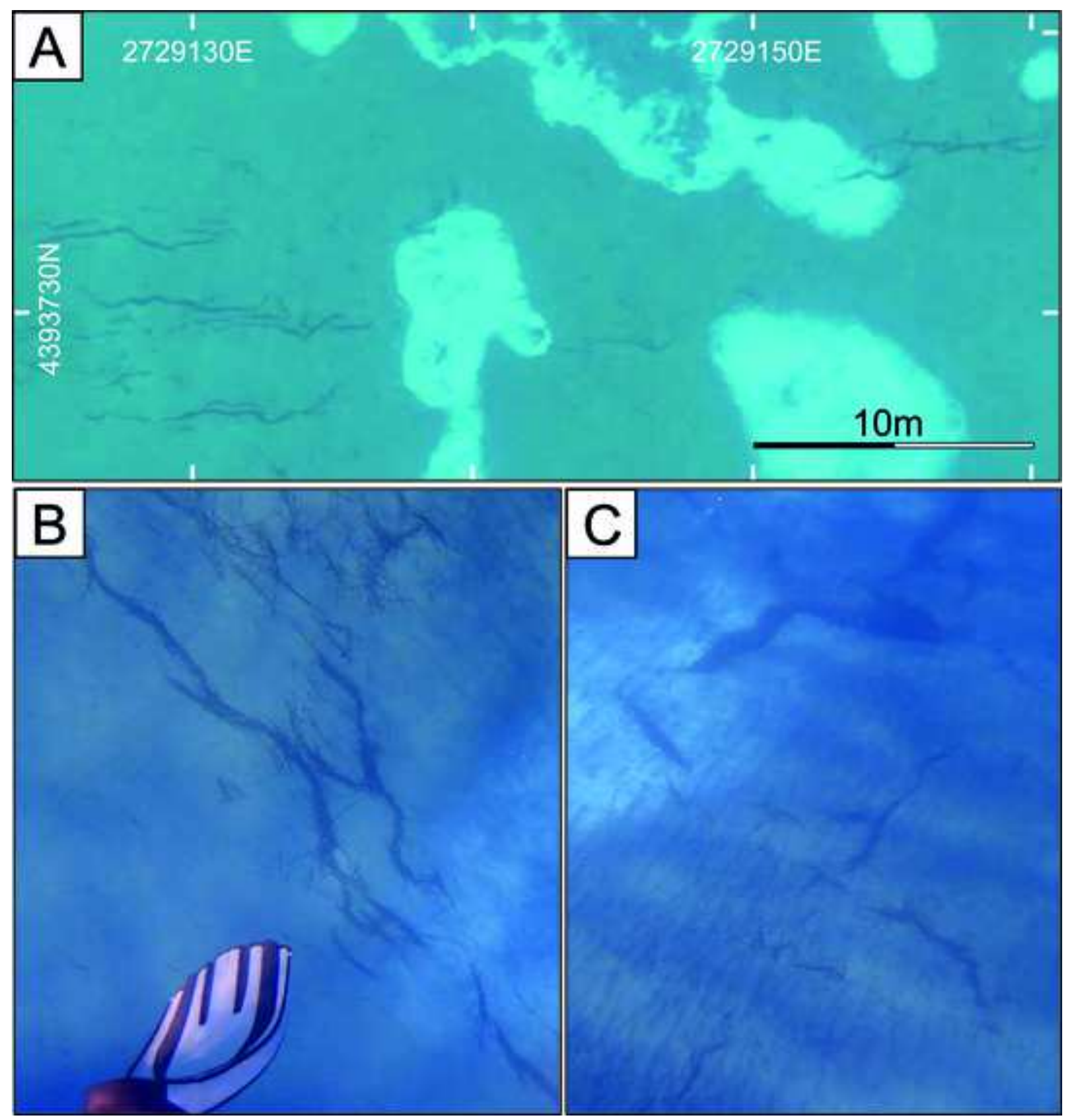

